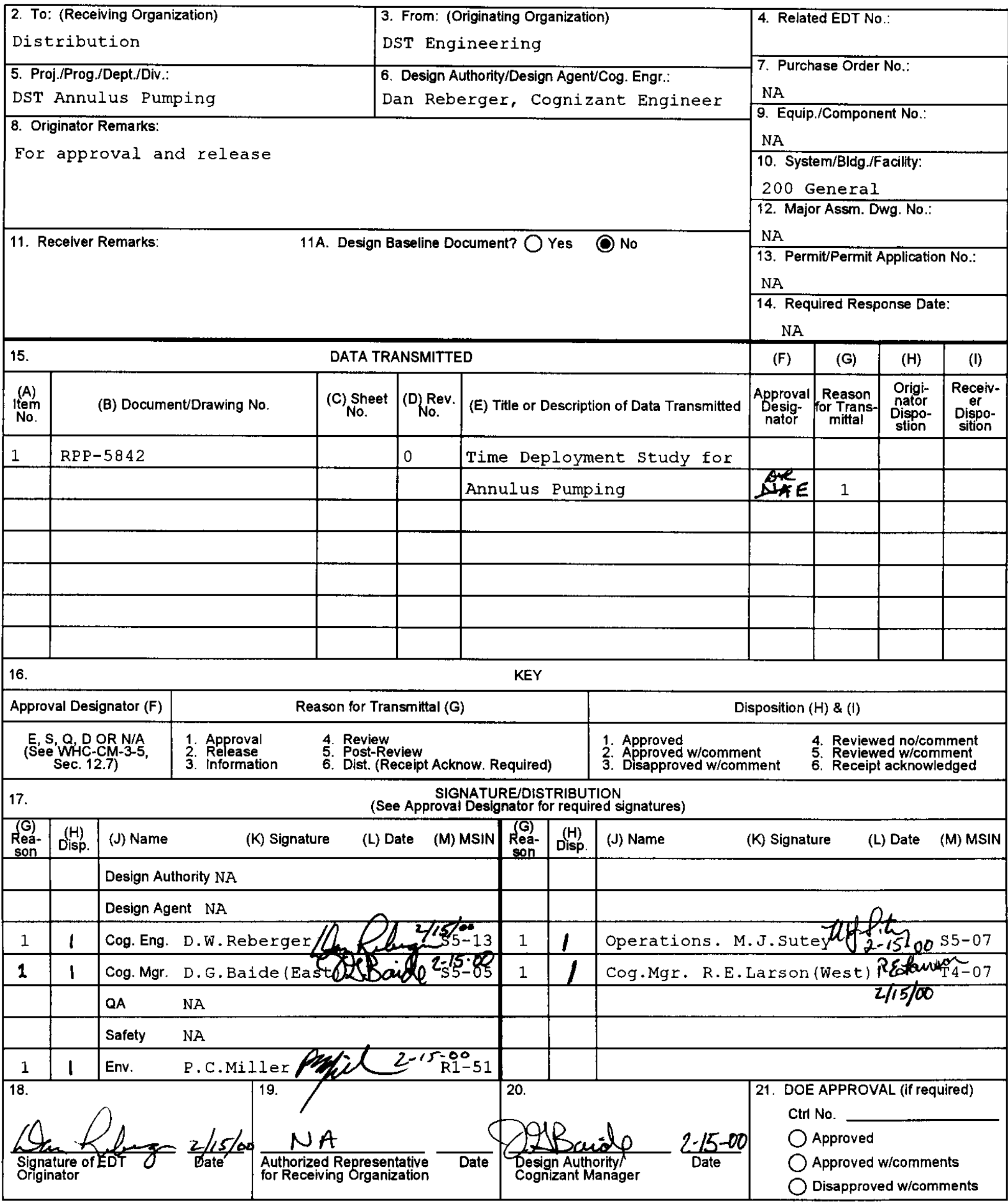




\title{
TIME DEPLOYMENT STUDY FOR ANNULUS PUMPING
}

\author{
D.W. RERTRCIRR \\ CH2M HILL HANFORD GROUP, INC \\ Richland, WA 99352 \\ U.S. Department of Energy Contract DE-AC06-99RL14047 \\ EDT/ECN: 622603 UC: \\ Cost Center: $74100 \quad$ Charge Code: 111273 \\ B\&R Code: EW3120071 Total Pages: 58
}

Key Words: Double-Shell Tank, DST, Annulus, Pumping, Secondary Containment, Leak

Abstract: This Time Deployment Study provides the proposed plan and schedules necessary to quickly deploy a pump and transfer system for removal of leaked waste from a Double-shell Tank annulus.

TRADEMARK DISCLAIMER. Roference horein to any epeclific commercial product, procese, or eervice by trade name, tredemark, manufecturer, or otherwiee, does not mecesearly consthute or imply lis endoreement, recommendation, or fevoring by the United States Government or any agency thereof or its contractors or subcontractors.

Pinted in the Uniked States of America. To obtain copies of this document, contact: Document Control Services, P.O. Box 850, Malietop H6-08, Richiand WA 99352, Phone (509) 372-2420; Fax (509) 376-4989.
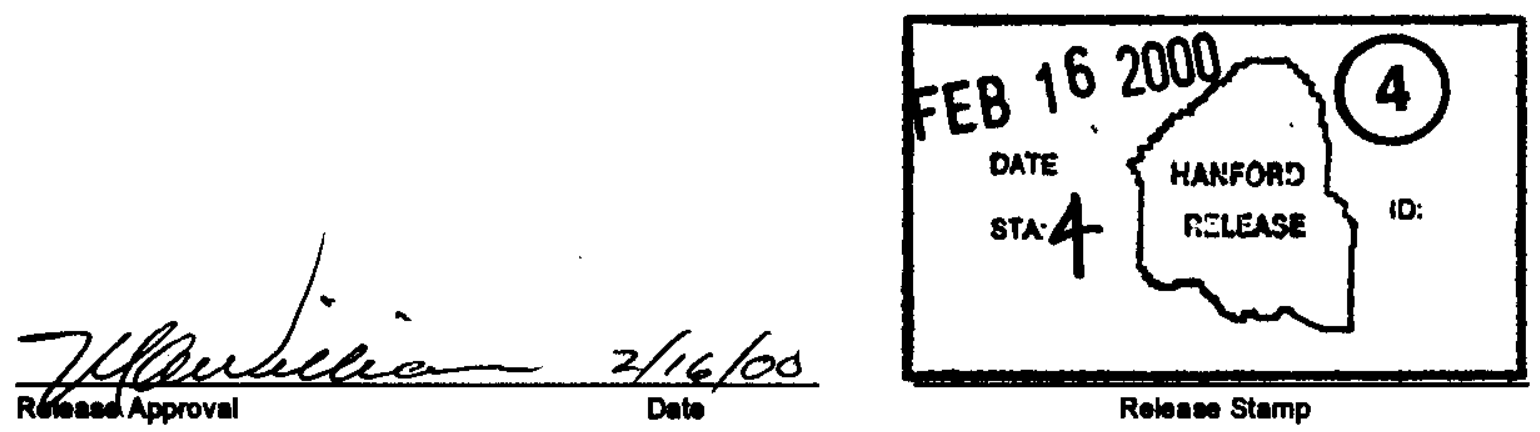

Release Stamp

\section{Approved For Public Release}




\title{
ENGINEERING STUDY
}

\section{TIME DEPLOYMENT STUDY FOR ANNULUS PUMPING}

\author{
FEBRUARY 2000
}

Prepared by

Fluor Federal Services

Richland, Washington 
TABLE OF CONTENTS

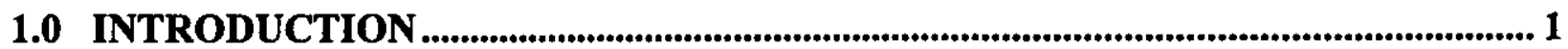

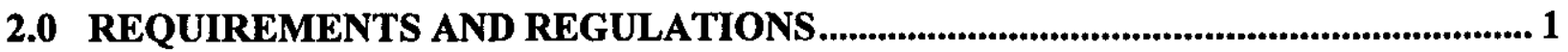

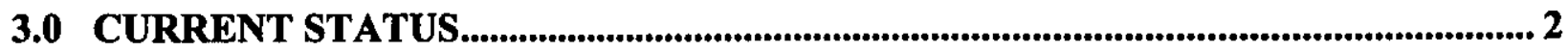

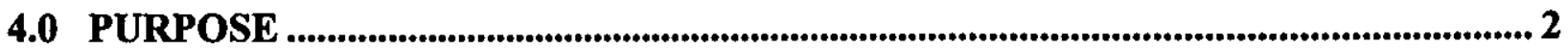

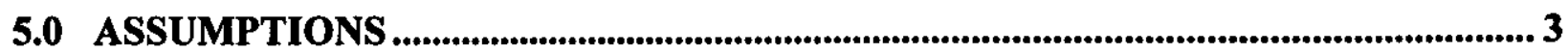

6.0 SYSTEM DESCRIPTION

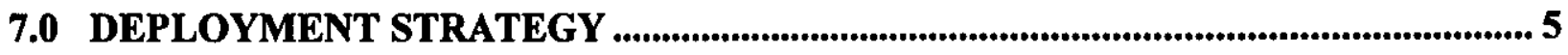

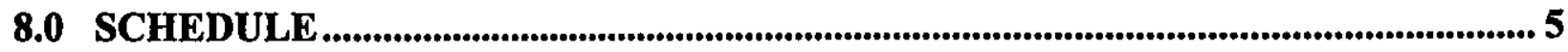

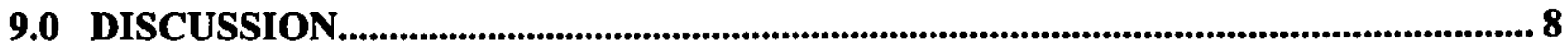

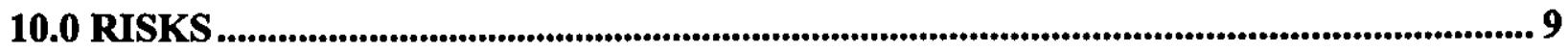

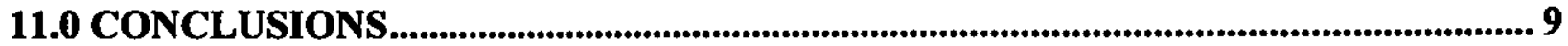

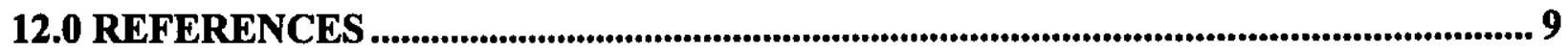

APPENDICES

Appendix A: Figure

Appendix B: Tables

Appendix C: Schedules

Appendix D: Estimates 
RPP-5842, Rev. 0

\section{ENGINEERING STUDY}

\section{TIME DEPLOYMENT STUDY FOR ANNULUS PUMPING}

\subsection{INTRODUCTION}

Radioactive wastes from processing irradiated uranium fuels have been stored as alkaline slurries in underground tanks at the Hanford Site. Single-shell tanks (SST) and double-shell tanks (DST) of various sizes were used for waste storage. Of the total 177 tanks, there are 28 DSTs. DSTs are located in AN, AP, AW, AY, AZ, and SY tank farms in the 200 East (200E) and 200-West (200W) Areas. The storage capacities of the DSTs vary from 980,000 to $1,140,000 \mathrm{gal}$ (ref 1). DSTs are designed and constructed as an integral steel structure, i.e., an inner shell within an outer shell, so that any leak from the inner shell is confined within the annulus without impacting the environment. The inner shell provides primary containment for the wastes and the outer shell provides secondary containment in the form of an annulus.

The annulus of a DST is equipped with a pump pit, leak detection probes, and other accessories (see figure 1 in Appendix A). The existing annulus pumps in the DSTs need to be revamped with a new system to reduce operating costs and reduce the time to deploy a pumping system. The new pumping system will minimize the likelihood of a release of waste into the environment; improve capability of waste removal to the maximum extent possible to comply with Washington Administrative Code (WAC) 173-303-640) and Code of Federal Regulations (CFR) 40 CFR 265.193.

This study addresses the time required to deploy an annulus pumping system designed to fit any DST after detection of a leak in the inner shell of the DST.

\subsection{REQUIREMENTS AND REGULATIONS}

DSTs utilized for the storage of radioactive wastes are subject to Resource Conservation and Recovery Act (RCRA) regulations. Ecology implements RCRA with the state's Dangerous Waste Regulations and the tank systems are regulated as treatment, storage, and disposal units (TSDs). TSDs are subject to the requirements applicable for the generation, transportation, storage, treatment, and disposal of hazardous wastes (ref 3). The Hanford Facility RCRA Permit (\#WA 7890008967), dangerous waste portion, issued by Ecology has been in effect since 1994 (ref 4)

Double-wall tank systems that are used to store or treat dangerous wastes shall contain a secondary containment system, "provided with a leak-detection system that is designed and operated so that it will detect the failure of either the primary or secondary containment structure or the presence or release of dangerous waste or accumulated liquid in the secondary containment system within twenty four hours, or at the earliest practical time,"(40 CFR 265.193(c)(3) and WAC 173-303-640(4)(c)(iii). Secondary containment (annulus) of the tanks shall be, "sloped or otherwise designed or operated to drain and remove liquids resulting from 
leaks, spills or precipitation. Spilled or leaked waste and accumulated precipitation must be removed from the secondary containment system within twenty-four hours, or in as timely a manner as is possible to prevent harm to human life and the environment..."

(40 CFR 265.193(c)(4) and WAC 173-303-640(4)(c)(iv).

\subsection{CURRENT STATUS}

DSTs contain ventilation channels that also function as drain channels in the insulating and/or supporting concrete to carry leakage to the annulus where the leakage is monitored by conductivity probes and radiation detectors. The integrity of all DSTs is categorized as "sound" as to their condition (ref 1). No DST leakage has ever been detected, However, in case of a leak in the inner shell, the annulus is designed to confine and prevent the release of waste into the environment, as required by state and federal regulations.

Currently, all DST farms, except AW farm, are provided with one, pit-mounted, vertical, turbine pump in the tank's annulus pit (one pump per farm), and the pump is moved if the inner shell of a different DST is determined to be leaking. Lacking a test facility for the pumps at the Site, performance tests or preventive maintenance for the annulus pumps is minimal. The use of a single, bulky, turbine pump for several tanks increases the costs and risks inherent in handling radioactive wastes. Due to physical constraints, it cannot be assured that wastes leaking from the inner shell can be removed, using existing pumps, within 24 hours or in a timely manner to meet the WAC or CFR regulatory requirements. In addition, if the existing turbine pump is used, the heel remaining after pumping will be at least 12 in.

An emergency annulus pumping system for the DSTs, capable of removing waste in the annulus, is planned for deployment on a fast-track basis to ensure safety, health, and environmental considerations and to comply with regulatory requirements. ARES, Inc., performed an engineering study to evaluate alternatives for annulus pumping (ref 2). They recommended emergency annulus pumping equipment, capable of providing reliable service and rapid deployment, within a package comprised of submersible pumps, prefabricated equipment, and pipe assemblies to be stored in a mobile trailer at the site (ref 2 and 5).

\subsection{PURPOSE}

The purpose of this study is to develop a detailed schedule to ensure rapid deployment of an annulus pumping package with pumps, jumpers, and other accessories. The study will help plan, procure, and implement a rapid deployment strategy of an annulus pumping system for any of the DSTs in $200 \mathrm{E}$ and $200 \mathrm{~W}$ Areas.

The study will identify all critical activities necessary to plan, organize, and schedule the deployment of a pumping system. Specific activities include preparation of engineering change notices (ECNs); work packages for the fabrication, installation, testing of pumps, jumpers, transfer lines, and other accessories and analysis of waste. 
After detecting and verifying the presence of waste in the annulus, deployment of the system will be initiated, upon notification to Washington Department of Ecology (Ecology). The system consists of pumps, jumpers, valves, pipes, electrical and pneumatic skids, and other components necessary for the transfer of waste. Because of differences in configuration and status of the drawings for the tanks, pits, and routes, the study also evaluates and compares several cases by assuming different degrees of readiness for fabrication and assembly of the components necessary for pumping.

\subsection{ASSUMPTIONS}

Depending on the efforts necessary to complete the prerequisites in terms of engineering, operations, maintenance, and fabrication, the schedules will determine the time required to complete all the tasks necessary to finish deployment of the pump systems. Two cases were considered to estimate the time and resources required to commence annulus pumping.

General assumptions applicable to both cases and assumptions that are case-specific are listed below:

- A leak in the inner shell of a DST is an emergency situation for planning, design, procurement, fabrication, and operations. Rapid mobilization of task teams is feasible.

- Operations Readiness Review will not be required for the necessary activities to proceed.

- Written approval from Safety Services and DOE for transfers from Watch List Tanks will be received prior to pumping the annulus.

- No plant force work review will be required.

- Pumps, jumpers, electrical skids, and all accessories can be stored in an enclosed trailer located in the 200E Area.

- Modifications are not required in the DST's annulus pits except the installation of a flanged pump and jumper assembly.

- No special controls due to unresolved safety questions (USQs) are applicable for AN, AP, $\mathrm{AW}, \mathrm{AY}, \mathrm{AZ}$ and SY tank farms and the pending USQ on tank SY-101 will not impact deployment operations.

- All utilities such as water, power, and air supply are available at the specified locations.

- Pumps shall be tested prior to installation in the annulus.

- Painting of the jumper assemblies is not required.

- Rigid jumpers are required only for central pump pit and annulus pump pit. In lieu of rigid jumpers, flexible jumpers can be utilized in other support pits.

- An empty DST will be available to receive waste from the annulus of the leaking tank.

- A turbine pump is not installed in the annulus of the leaking tank.

- Pressure testing of the annulus transfer line is successful.

In addition to the general assumptions common to all the cases, specific assumptions pertaining to the following two cases, considered as separate scenarios, are listed below: 


\section{Case 1: Fabricate Jumpers}

- Submersible pumps are available and require only testing and minor assembly

- Rigid jumper drawings will require update by ECNs

- Rigid jumpers will be fabricated from available components in storage.

\section{Case 2: Prefabricated Jumpers}

- Submersible pumps are available and require only testing and minor assembly

- Rigid jumpers are fabricated and available in storage.

The schedules for the deployment of pumps and jumper assemblies required for annulus pumping would include the following activities:

- Pressure test annulus transfer line

- Upgrade annulus leak detector

- Fabricate rigid jumpers

- Perform waste compatibility analysis

- Test annulus pump

- Install pump and jumpers

- Leak-test route

- Operations activities

- Transport and connect electrical/pneumatic skids.

The timeliness for each activity shall reflect the important tasks necessary to complete the activity.

\subsection{SYSTEM DESCRIPTION}

The annulus pumping system in the DST is capable of removing wastes leaking from the annulus. The system components and the transfer route from the leaking tank to the receiving tank are shown in figure 1. The system will be designed to pump the bulk of the waste leaked from the primary shell of the DST with a submersible pump, and pump any residual heel with a positive displacement pump. Both pumps will be assembled as an integral unit to facilitate installation below the annulus pit.

The submersible pumps, with a flowrate of $40 \mathrm{gpm}$ at $160 \mathrm{ft}$ of total head, will be utilized to lower the level of waste in the annulus to the inlet port of the pump. The positive displacement pump, at a flowrate of 2 to $5 \mathrm{gpm}$, will pump the residual waste left in the annulus. Small leaks with trickling flows will require the positive displacement pump only. Selected characteristics of the pumps are conservative in that the waste transfer from the leaking tank to any of the receiving tanks can be accomplished without significant loss of time. Retrieval of the wastes with the pumps in the primary tank is not addressed in this study. The pipe routing used for pumping the primary tank or annulus to a receiving DST is the same and therefore cannot be performed simultaneously. 


\subsection{DEPLOYMENT STRATEGY}

Based on positive leak indications from the detection probes or ventilation system monitors in the annulus, a leaking inner shell of a DST will be elevated for intense monitoring to confirm the leak. Upon verification, Ecology will be notified in no less than 24 hours. The following strategy will be employed to mitigate the consequences of the leak.

Work packages are common to all the activities involving field operations. The preparation and approval of the packages will be staggered in such a way that distribution is balanced for the planners and prioritized according to the critical needs of the schedule.

Several work packages are necessary to complete the activities in the schedule. Because this is an emergency action plan, personnel will be required to work day and swing shifts $(8 \mathrm{hr} / \mathrm{shift})$, including weekends. The tasks will receive unlimited resources and the schedules will reflect the intense nature of the work. The planning, operation, and engineering resource commitments will be similar in scale to those used during November 1999 in 200E Area for Tank 241-ER-311 to implement the schedule of activities on a fast-track basis. For example, within a matter of days of detecting the flammable gas concentration in the tank, equipment was assembled and installed to purge the tank with an inert gas to eliminate the hazard. Work packages were completed within 24 hours to allow completion of the tasks. Concurrent approvals for the proposed actions by DOE, Ecology, and the Washington State Department of Health were successfully coordinated to implement the activity.

Any new safety issues associated with pumping wastes from a leaking DST annulus may invoke the use of Limiting Conditions of Operations - Emergency Exceptions (LCO 3.0.7):

"If an emergency situation develops that is not treated in the Technical Safety Requirements (TSRs), operations personnel are expected to use their training and expertise to take actions to correct and mitigate the situation. Operations personnel may take actions that depart from a requirement in the TSRs provided an emergency exists and these actions are needed immediately to protect the health, safety of the public and on-site workers."

\subsection{SCHEDULE}

The schedules for the deployment of the DST annulus pumping system consist of two scenarios-Case 1: Fabricate Jumpers, and Case 2: Prefabricated Jumpers (see Appendix C). The schedules contain all key activities and other activities. Schedules are based on the number of days starting with the notification to Ecology of the leak as day zero.

The software used for the schedule will not show activity duration of less than a day. Though some activities may consume only a few hours, they are shown as taking a day. 
Planning, operational, and engineering activities included in the schedules were reviewed by the respective work groups. Concurrent team assignments will be required to complete the tasks within the proposed schedule.

In Case 1, the activities associated with Fabricate Rigid Jumpers are in the critical path followed by the removal of equipment installed, or yet to be installed, under Project W-314, Tank Farm Restoration and Safe Operations. It takes 10 days to complete all the activities under Case 1 and start pumping the DST annulus. However, in Case 2, it takes only 9 days to complete the activities. The activities required for the transfer of wastes from the annulus are similar, except that in Case 2, activities associated with Fabricate Rigid Jumpers are excluded and removal of project W-314 hardware becomes the long-duration activity and critical to the deployment.

The activities identified in the schedules are discussed below:

\subsection{Pressure Test Transfer Lines}

Pressure tests of annulus transfer lines between the annulus pit and central pump pit will be done at the operating pressure of the transfer system. Tents are set up over the pits and other work areas to avoid release of contamination into the atmosphere. Tent setup for any initial phase of operation will be left in place until all scheduled activities within the pits are completed.

For waste transfers from the annulus, the existing tank farm piping, pump pits, and valve pits will be used. Currently, the transfer piping system is in use for various transfers and the integrity of the system is maintained. However, the annulus transfer lines between the annulus pit and the central pump pit are not in use. The existing annulus transfer lines for various tank farms are listed in Table 1, shown in Appendix B. Of the 32 annulus pipe sections, 26 sections have secondary containment. Transfer piping in tank farms $A Y$ and $A Z$ is direct-buried with no encasement. The annulus transfer pipes between the annulus pit and central pump pit have not been pressure-tested for a number of years, but each line will be tested (using water) to meet the standards for pressure tests prior to the connection with pits.

\subsection{Upgrade Annulus Leak Detector}

The leak detector in the annulus pit requires an upgrade because the annulus that contains waste is considered a flammable gas environment. Upgrading the detector involves reducing supply voltage to a level considered safe for flammable gas atmosphere in the annulus pit.

\subsection{Fabricate Rigid Jumpers}

Jumpers for the central and annulus pump pits (one each) will be fabricated per a shop traveler. A shop traveler is a document comparable to a work package, but specifically meant for shop activities. Designs for all tank farm jumpers, as listed in Table 2 shown in Appendix B, are already completed. However, the drawings need to be updated and ECNs will be required before the jumpers can be fabricated. 


\subsection{Waste Compatibility}

In removing the waste from the annulus, waste must be compatible with the pumping criteria. Dilution of the waste may become necessary to achieve consistency and fluid characteristics necessary to match the design criteria of the annulus pump. Tank waste compatibility issues will be assessed using past tank sample analyses, if possible. If new sample data is required, samples will be obtained. Engineering will perform an evaluation of waste pumping characteristics and specify a dilution ratio, if necessary.

\subsection{Test Pumps}

Pumps will be tested routinely to ensure reliability during operations. In addition, a pre-test will be completed before placement of pumps in the annulus to enhance operational assurance after deployment.

\subsection{Install Pump}

Upon successful testing, the pump will be installed in the annulus and the supports will be mounted at the annulus pit.

\subsection{Install Jumpers}

A flexible jumper is a connection necessary for any selected pit for which a rigid jumper is not available. Six flexible jumpers are available in stock for annulus pumping. Flexible jumpers are not suitable for all waste pumping operations. For this schedule, only one flexible jumper is assumed necessary to connect the annulus system into the normal transfer system. Two rigid jumpers, one each, will be installed in the annulus and central pump pits.

The mission of project W-314 is to upgrade the existing tank farm facilities and systems to improve reliability of operation during waste storage and transfer operations. The project is in various stages of implementation. The upgrades include, but are not limited to, new valve manifold assemblies to replace existing jumpers in selected pits, leak detection, and cathodic protection capabilities to enhance compliance and durability of the systems. The project hardware for jumpers and valves in the central pump pits and the instrumentation controls associated with the mechanical equipment are more difficult to remove compared to existing equipment. Removal of project W-314 hardware is essential for the installation of jumpers in the central pump pit. Access openings for valve handles in the coverblock need to be fitted with plugs to ensure worker safety and to prevent spread of contamination.

\subsection{Leak Test Route}

Leak testing of the newly installed jumpers is performed using a water-flow check. The new jumper connections in the pits are inspected for leaks, by the use of cameras installed in the pits. The normal system transfer piping is being used routinely and no testing will be necessary. The leak check is a technical safety requirement performed prior to proceeding with a waste transfer. 


\subsection{Operations/Activities}

Existing transfer procedures for pumping the annulus will be available. The procedures may require some minor updates. The equipment checks involve verifying that essential equipment required for the transfer (e.g., leak detectors, ventilation) are calibrated and tested for operability. Valve lineup performs the procedural valve positioning necessary to route the waste to the appropriate receiver tank. Safety Services and DOE approvals are required prior to pumping Watch List tanks such as 103-AN, 104-AN, 105-AN, 101-AW and 101-SY (ref 6). This approval is not required for any other DSTs.

\subsection{Field Locate Electrical/Pneumatic Skids}

Moving electrical and pneumatic skids for the pumps and electric controls and hooking up to the Site utilities or other facilities will be the last step in completing the schedule of activities to get the annulus pumping started.

\subsection{DISCUSSION}

It is clear from the schedules that removal of project W-314 hardware is more critical to start pumping the DST annulus than the activities associated with installation of jumpers. Both Case 1 and 2 require the same duration ( 9 to 10 days) to complete the activities before annulus pumping can start. Though a difference of a day exits between Case 1 and 2, it is not significant, given the sensitivity of the software, to show time duration less than 1 day. Therefore, prefabrication of jumpers does not realize a gain in schedule.

Of all the tasks, jumper prefabrication is an activity that can be completed independently without impacting the schedule. Requirements for the fabrication of jumpers vary from pit to pit due to unique as-built dimensions. In the absence of knowledge as to which pits may be involved in a transfer, should a leak occur, prefabrication will require over 50 unique jumpers. The engineering costs and other expenditures associated with planning, design, fabrication, storage, and upkeep of the jumpers will not be cost effective.

The fabrication of jumpers can proceed concurrently with the removal of project W-314 hardware, an activity that must precede the installation of the jumpers in the central pump pit. Project W-314 equipment removal is shown as the critical activity in both cases. However, any time reduction for the project W-314 activity would result in another activity immediately becoming the critical path. This is due to the significant number of tasks necessary to allow initiation of annulus pumping.

The schedules exemplify the time constraints involved in the deployment of the pumps in the annulus. The fact that both Case 1 and 2 result in little difference is because there are so many activities necessary for the implementation of annulus pumping. 


\subsection{RISKS}

At least one tank in each tank farm is equipped with a turbine pump in the annulus pit. Both schedules in this study are based on the assumption that the existing pumps will be removed and the riser will be available for the installation of the new pumps. Two cost estimates for the removal of all the pumps-with and without contamination of the components-are shown in Appendix D. The cost for removing each pump prior to contamination is $\$ 110,000$, and after contamination, the cost is $\$ 1,100,000$. Under an emergency, if it is determined that the leaking tank is fitted with the turbine pump in the annulus pit, the situation will delay ready access to the riser and impact the schedule.

\subsection{CONCLUSIONS}

The schedules indicate that the activities necessary to initiate annulus pumping will take approximately 10 days. Speeding up fabrication of jumpers has little effect on the overall schedule duration. This is largely due to the significant number of activities that must be completed in a short time.

Prefabrication of jumpers for the central and annulus pits, for rapid deployment of annulus pumping, is considered unnecessary. Having all the components on hand to build the jumpers is more cost-effective than fabricating 56 individual jumpers.

\subsection{REFERENCES}

1. Fluor Daniel Hanford, Inc. October 1999. Waste Tank Summary Report for Month Ending August 31, 1999. HNF-EP-0182-137. Richland Washington.

2. ARES, Inc. April 1999. Double-Shell Tank Annulus Pumping Alternative Evaluation. HNF-4241. Richland, Washington.

3. Pacific Northwest National Laboratory. July 1998. Hanford Site Environmental Report for FY 1997. Richland, Washington.

4. Pacific Northwest National Laboratory. September 1999. Hanford Site Environmental Report for the Calendar Year 1998. Richland, Washington.

5. Lockheed Martin Hanford Company. March 1999. Double-Shell Tank Emergency Pumping Guide. HNF-3483, Rev. 1. Richland, Washington.

6. Lockheed Martin Hanford Company. March 1999. Operating Specifications for Watch List Tanks. OSD-T-151-00030. Richland, Washington. 
RPP-5842, Rev. 0

APPENDIX A

FIGURE

A - 0 


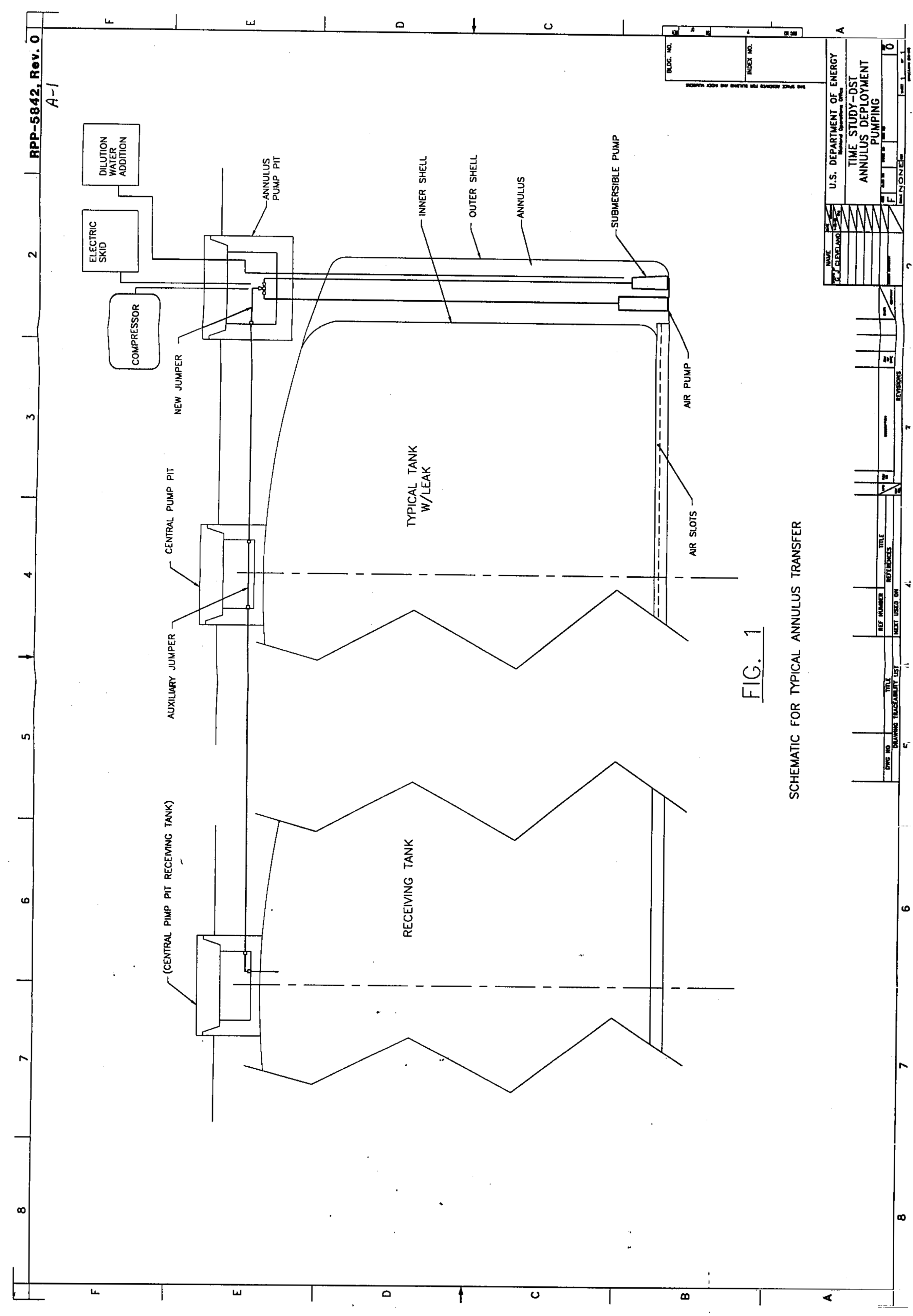




\section{APPENDIX B}

\section{TABLES}

Table 1: Identification of Annulus Transfer Line

Table 2: Annulus and Primary Tank Pump-out Jumper Drawings 
RPP-5842, Rev. 0

Annulus

\begin{tabular}{|c|c|c|c|c|}
\hline Tank & Transfer Line & \multicolumn{3}{|l|}{ Encasement } \\
\hline $101-\mathrm{AN}$ & $\mathrm{PW}-471$ & \multirow{2}{*}{\multicolumn{3}{|c|}{ PIPE-IN-PIPE }} \\
\hline $102-\mathrm{AN}$ & $\mathrm{PW}-472$ & \multirow{2}{*}{\multicolumn{3}{|c|}{$"$}} \\
\hline $103-\mathrm{AN}$ & $\mathrm{PW}-473$ & & & \\
\hline $104-\mathrm{AN}$ & PW- 474 & \multicolumn{3}{|l|}{$"$} \\
\hline $105-A N$ & PW-475 & \multicolumn{3}{|l|}{$"$} \\
\hline $106-\mathrm{AN}$ & $P W-476$ & \multicolumn{3}{|l|}{$"$} \\
\hline $107-\mathrm{AN}$ & $\mathrm{PW}-477$ & \multicolumn{3}{|l|}{$"$} \\
\hline 101-AP & $\mathrm{PW}-811$ & \multicolumn{3}{|c|}{ PIPE-IN-PIPE } \\
\hline $102-\mathrm{AP}$ & PW-812 & \multicolumn{3}{|c|}{ " } \\
\hline 103-AP & $\mathrm{PW}-813$ & \multicolumn{3}{|l|}{$"$} \\
\hline 104-AP & $\mathrm{PW}-814$ & \multicolumn{3}{|l|}{$"$} \\
\hline $105-\mathrm{AP}$ & $\mathrm{PW}-815$ & \multicolumn{3}{|l|}{$"$} \\
\hline $106-\mathrm{AP}$ & $\mathrm{PW}-816$ & \multicolumn{3}{|l|}{ " } \\
\hline $107-A P$ & $\mathrm{PW}-817$ & \multicolumn{3}{|l|}{$"$} \\
\hline $108-\mathrm{AP}$ & $\mathrm{PW}-818$ & \multicolumn{3}{|l|}{$"$} \\
\hline $101-\mathrm{AW}$ & $\mathrm{PW}-471$ & \multicolumn{3}{|c|}{ PIPE-IN-PIPE } \\
\hline 102-AW & $\mathrm{PW}-472$ & \multicolumn{3}{|c|}{ " } \\
\hline 103-AW & $\mathrm{PW}-473$ & \multicolumn{3}{|l|}{$"$} \\
\hline 104-AW & $\mathrm{PW}-474$ & \multicolumn{3}{|l|}{ " } \\
\hline 105-AW & $\mathrm{PW}-475$ & \multicolumn{3}{|l|}{$"$} \\
\hline 106-AW & $\mathrm{PW}-476$ & \multicolumn{3}{|l|}{$"$} \\
\hline \multirow[t]{2}{*}{ 101-AY } & $P W-4531$ & NONE & line routed to $A Y-01 A$ & Pit) \\
\hline & $P W-4528$ & NONE & (line routed to Tank) & \\
\hline \multirow[t]{2}{*}{$102-\mathrm{AY}$} & $P W-4532$ & NONE & (line routed to $\mathrm{AY}-02 \mathrm{~A}$ & Pit) \\
\hline & $\mathrm{PW}-4529$ & NONE & (line routed to Tank) & \\
\hline $101-\mathrm{AZ}$ & $\begin{array}{l}\mathrm{PW}-4623 \\
\mathrm{PW}-4620\end{array}$ & \multicolumn{3}{|c|}{$\underset{" \text { PIPE-IN-PIPE }}{\text { " }}$} \\
\hline $102-\mathrm{AZ}$ & PW-4609 & \multicolumn{3}{|c|}{ NONE } \\
\hline & PW- 4610 & \multicolumn{3}{|l|}{ NONE } \\
\hline $101-S Y$ & $\mathrm{PW}-478$ & \multicolumn{3}{|c|}{ PIPE-IN-PIPE } \\
\hline $102-S Y$ & PW- 475 & \multirow{2}{*}{\multicolumn{3}{|c|}{ " }} \\
\hline $103-$ & $\mathrm{PW}-479$ & & \\
\hline
\end{tabular}

TABLE 1

B-1 


\section{ANNULUS AND PRIMARY TANK PUMP-OUT JUMPER DRAWINGS}

AN Primary Tank Transfer Jumper

Annulus Jumper Central Pit

Annulus Jumper Annulus Pit

AP Primary Tank Transfer Jumper

Annulus Jumper Central Pit

Annulus Jumper Annulus Pit

AW Primary Tank Transfer Jumper

Annulus Jumper Central Pit

Annulus Jumper Annulus Pit

AY Primary Tank Transfer Jumper (D Pit)

Annulus Jumper Central Pit

Annulus Jumper Annulus Pit to Tank

Annulus Jumper Annulus Pit to Pit

AZ Primary Tank Transfer Jumper

Annulus Jumper Central Pit

Annulus Jumper Annulus Pit to Tank

Annulus Jumper Annulus Pit to Pit

SY Primary Tank Transfer Jumper

Annulus Jumper Central Pit

Annulus Jumper Annulus Pit
$\mathrm{H}-2-72026$

H-2-94863

H-2-72025

H-2-72028

H-2-90725

H-2-90726

H-2-90729

H-2-70445

$\mathrm{H}-2-70466$

H-2-70467

H-2-70468

H-2-70470

H-2-70444

H-2-70451

H-2-70772

H-2-70774

H-2-64457

H-2-64441

H-2-64458

H-2-64436

H-2-64457

H-2-64441

H-2-64458

H-2-46251

H-2-76536

H-2-76537

H-2-37800

H-2-68388
AN-01A, 02A, 06A, 07A

AN-03A, 04A, 05A

Assembly 1 AP-02A, 04A, 05A, 07A

Assembly 2 AP-01A, 03A, 06A, 08A

AW-01A, 03A, 04A, 05A, 06A

AW-02E

AY-01D

AY-02D
SY-01A \& 03A

SY-02A

TABLE 2 


\section{APPENDIX C}

\section{SCHEDULES}

Case 1, Fabricate Jumpers.....................................Page C-1

Case 2, Prefabricated Jumpers.................................Page C-4 


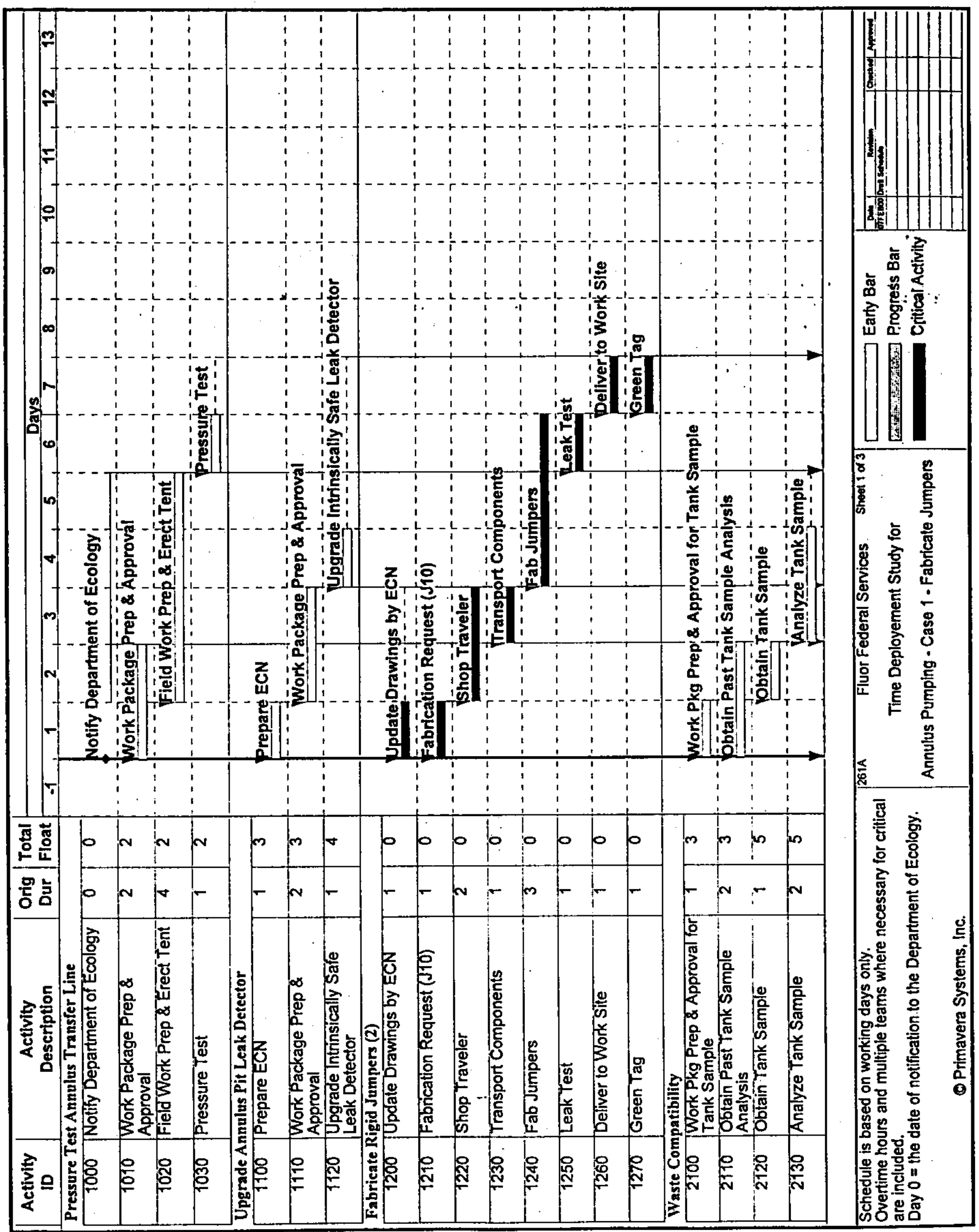




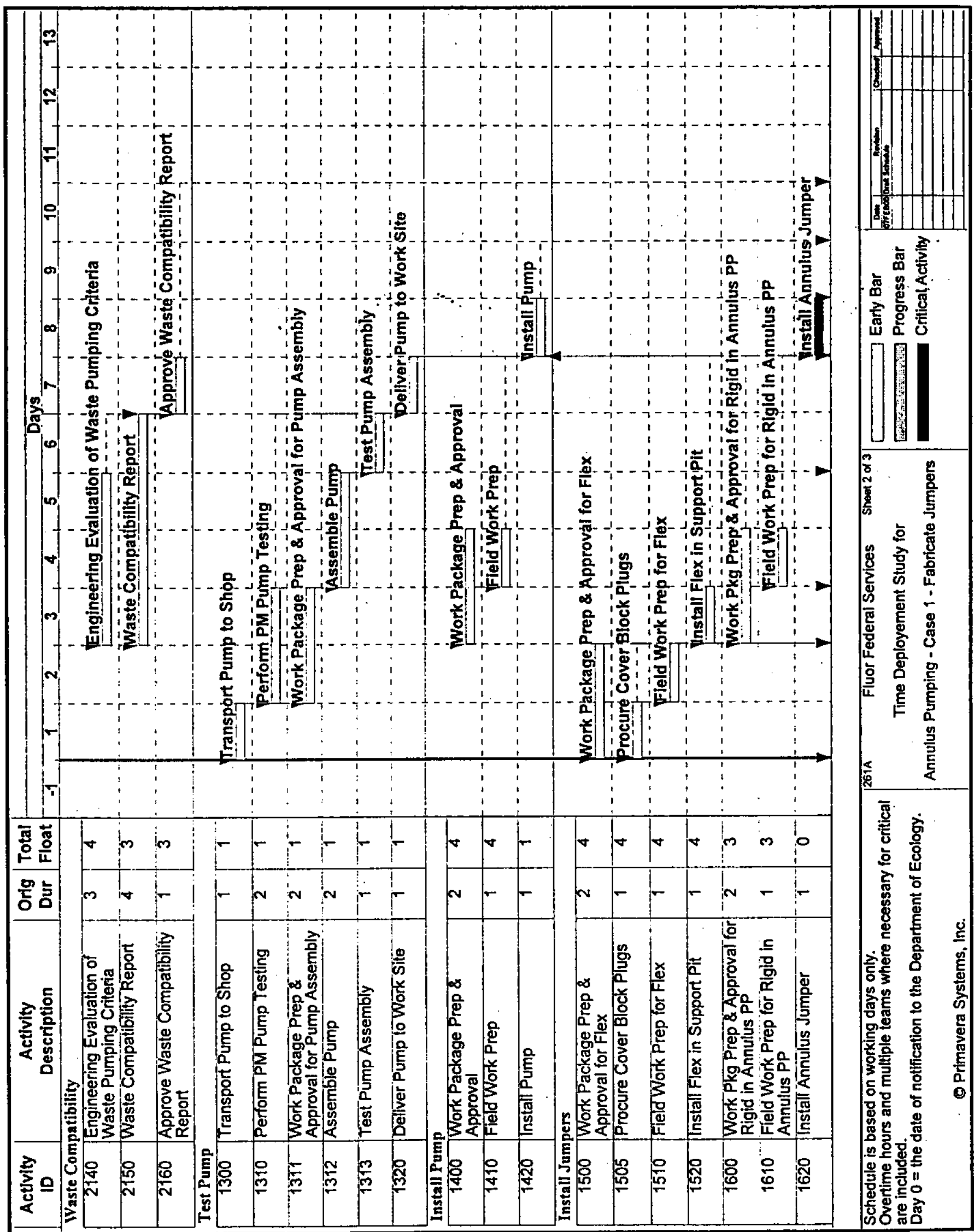




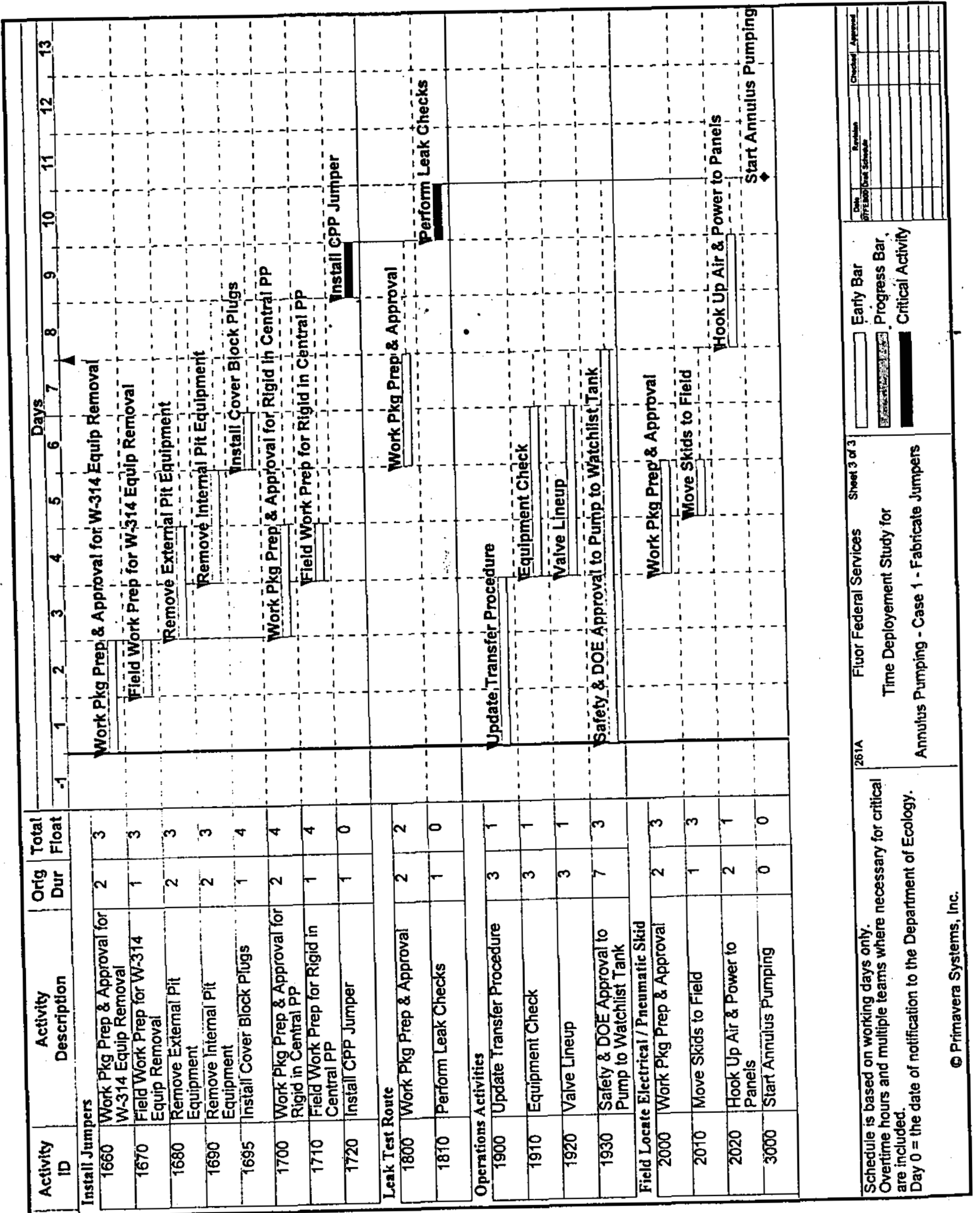


RPP-5842, Rev. 0

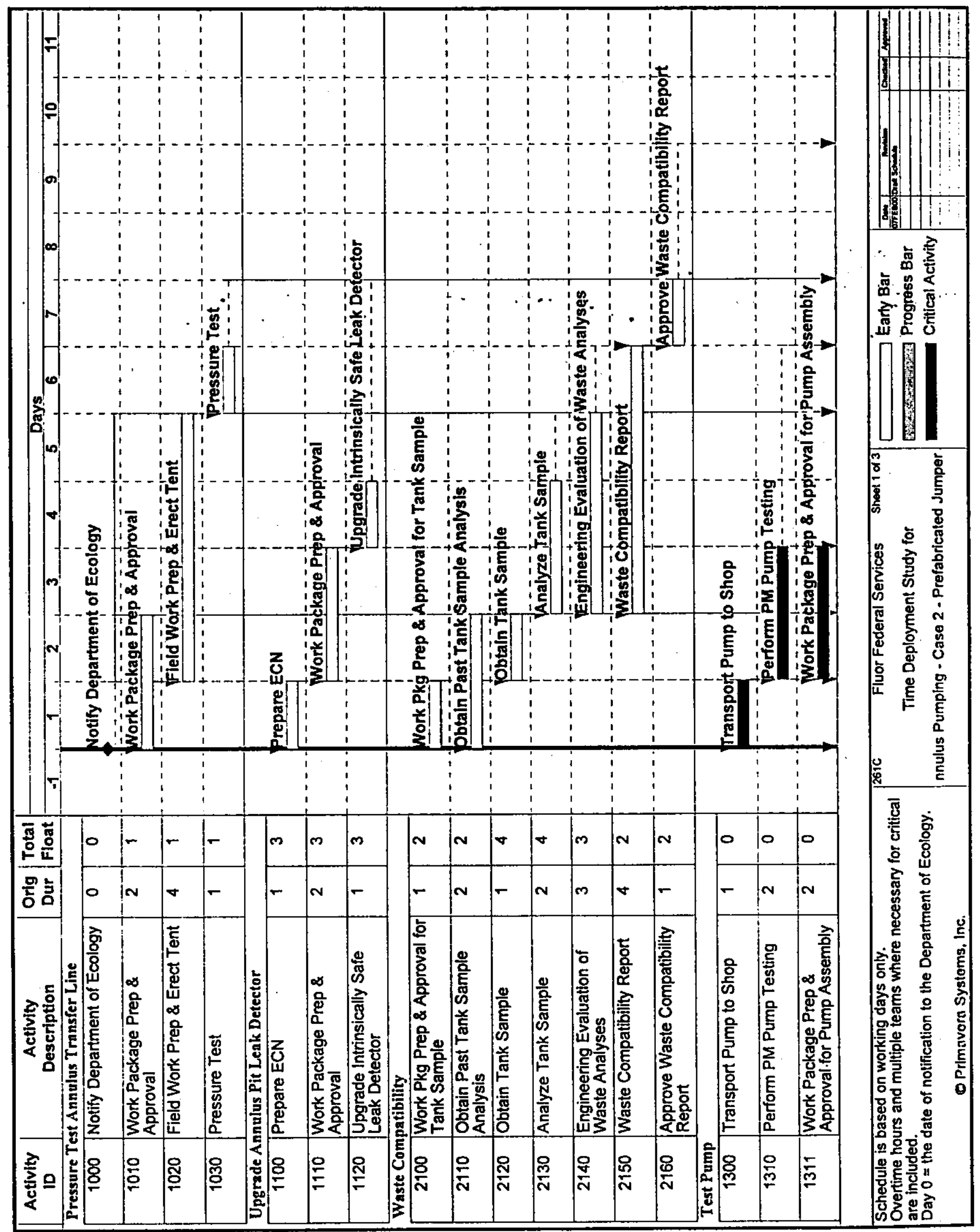




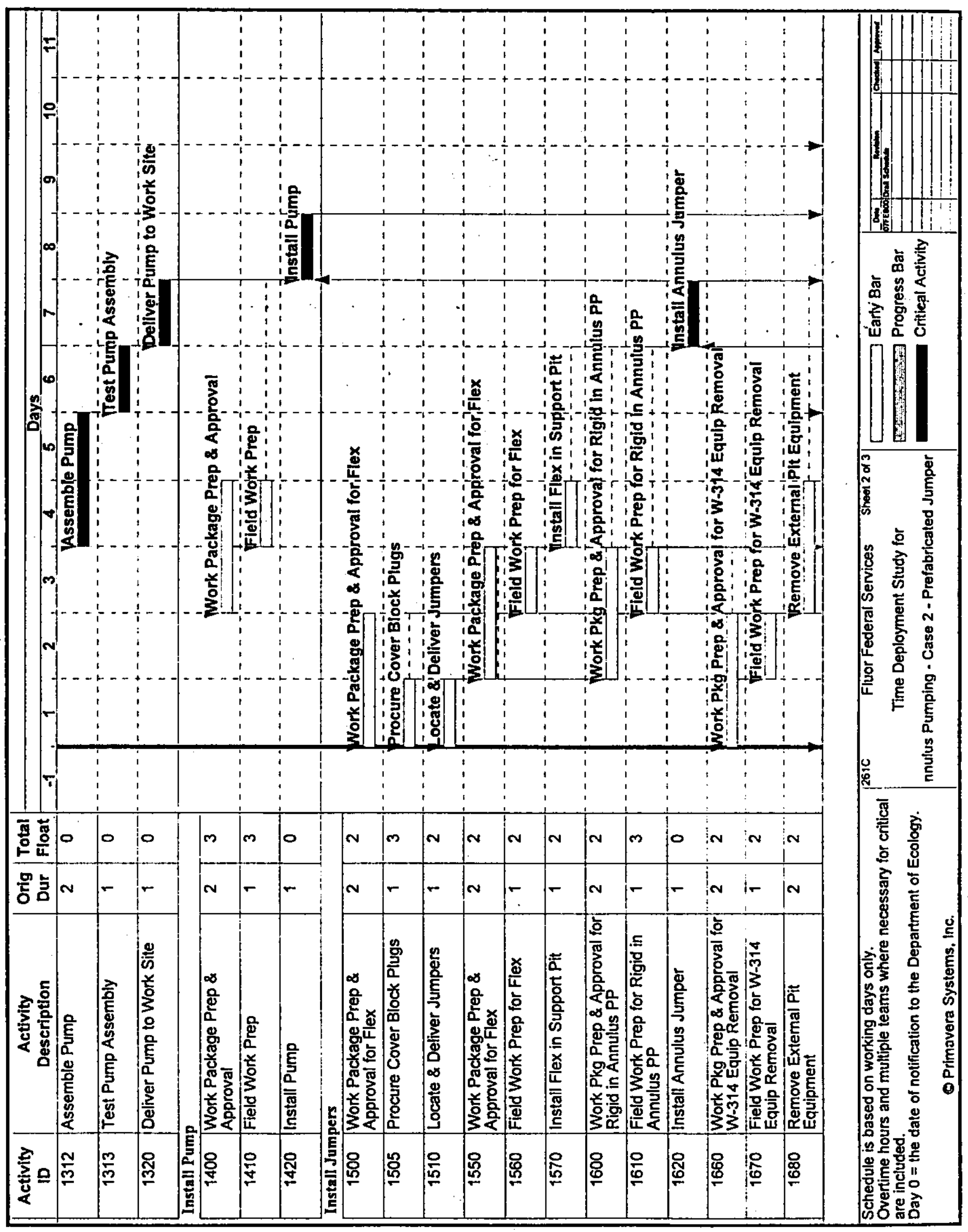


RPP-5842, Rev. 0

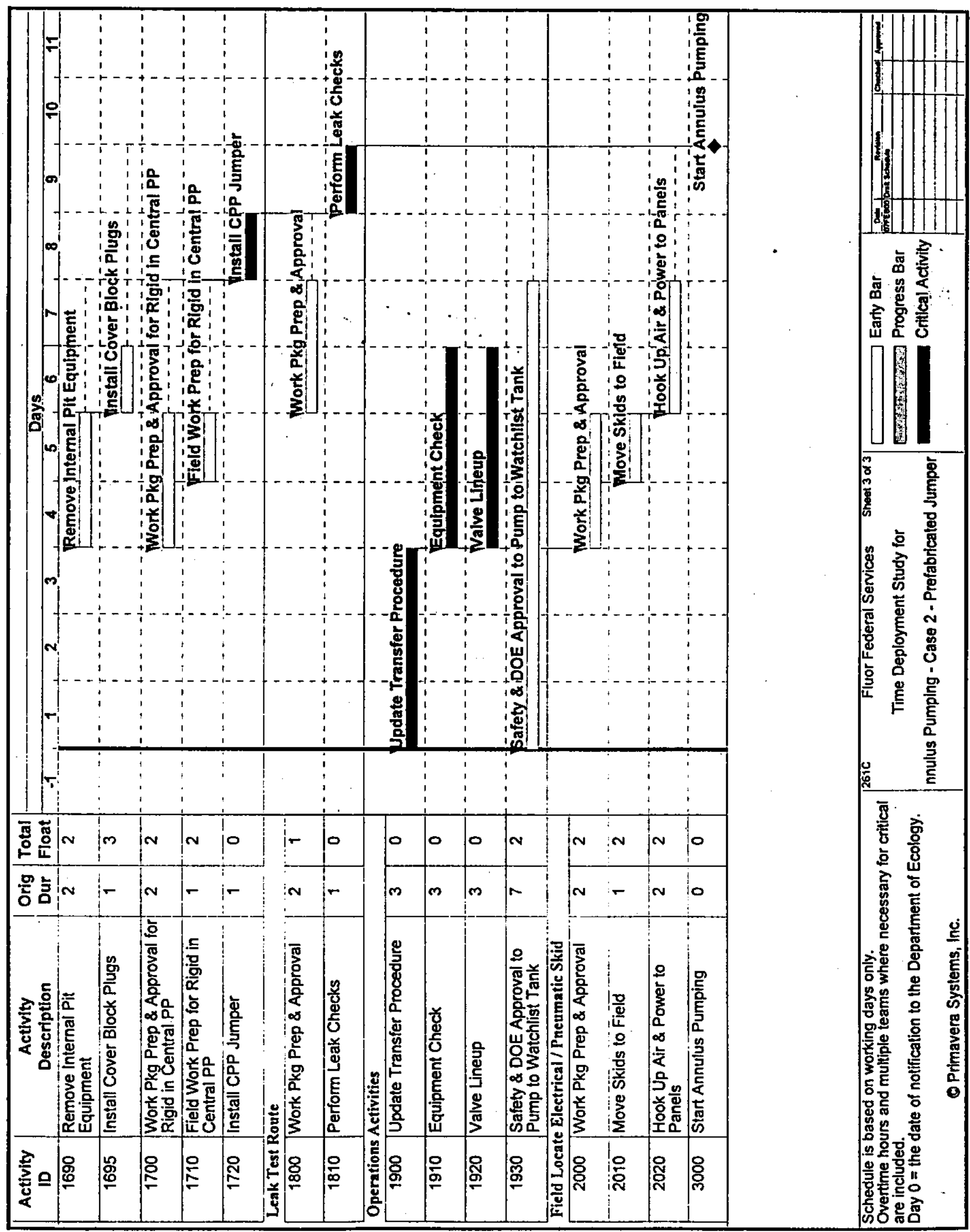




\section{APPENDIX D}

\section{ESTIMATES}

Clean Pump Removal.....................................................Page D-1

Contaminated Pump Removal.....................................Page D-15 
RPP-5842, Rev. 0
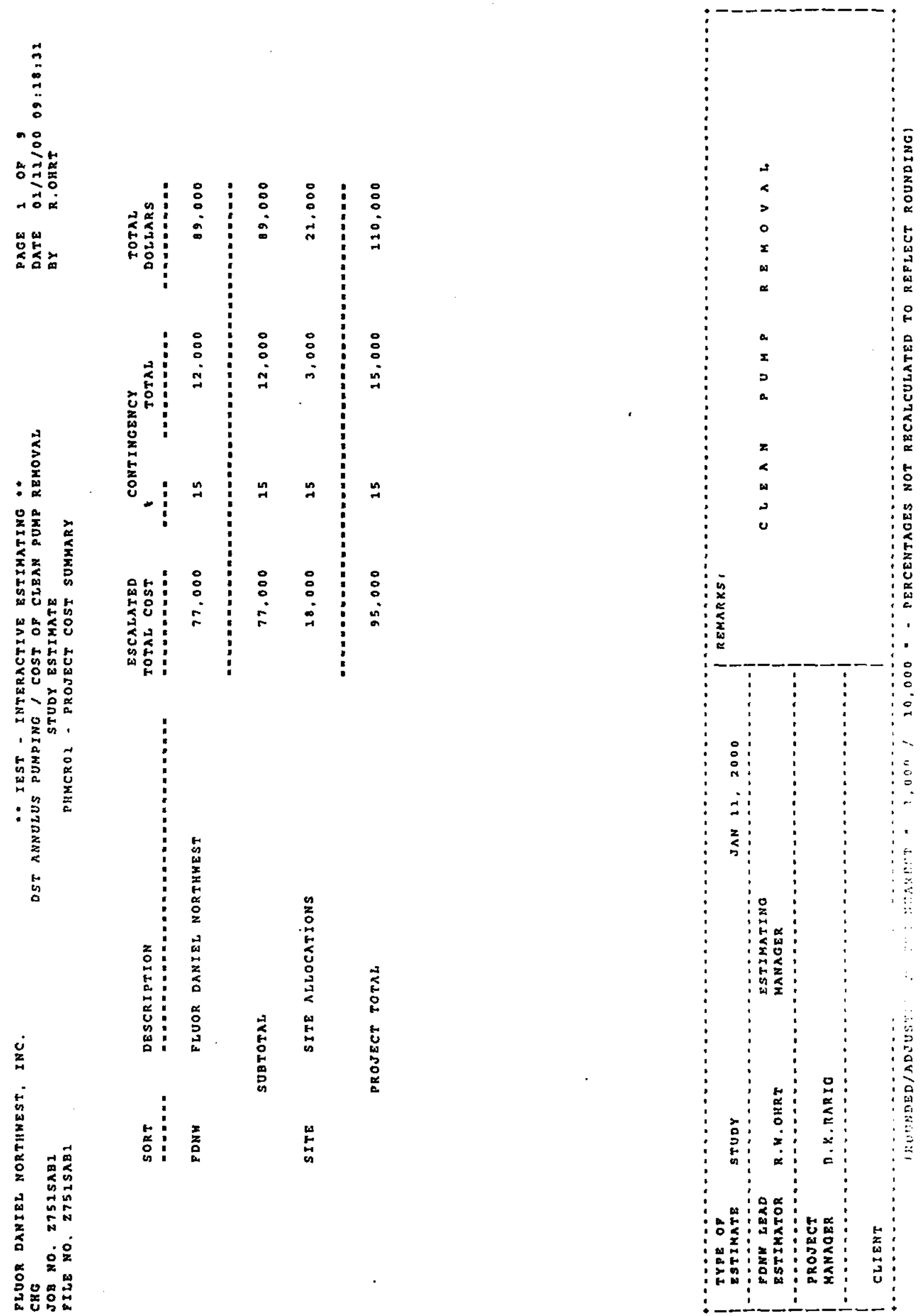


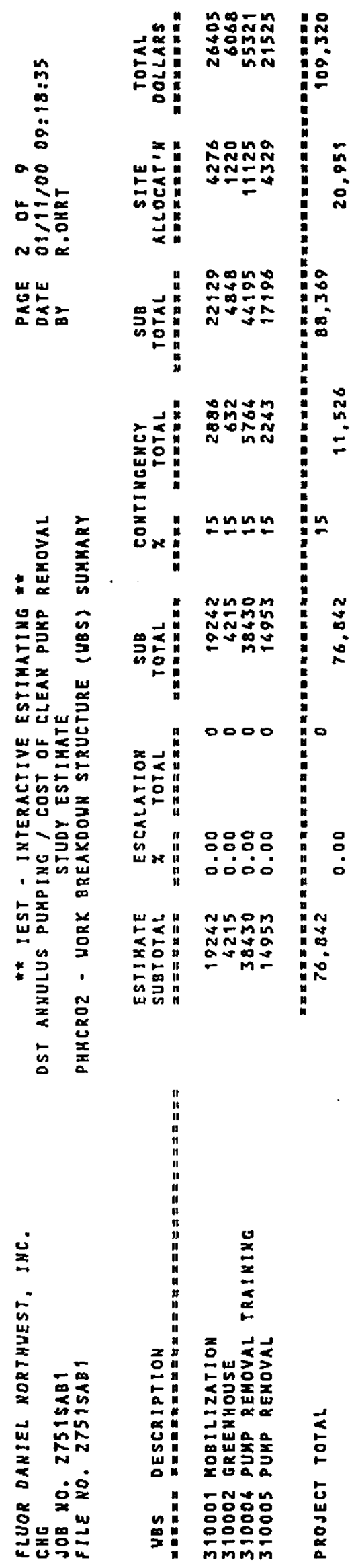




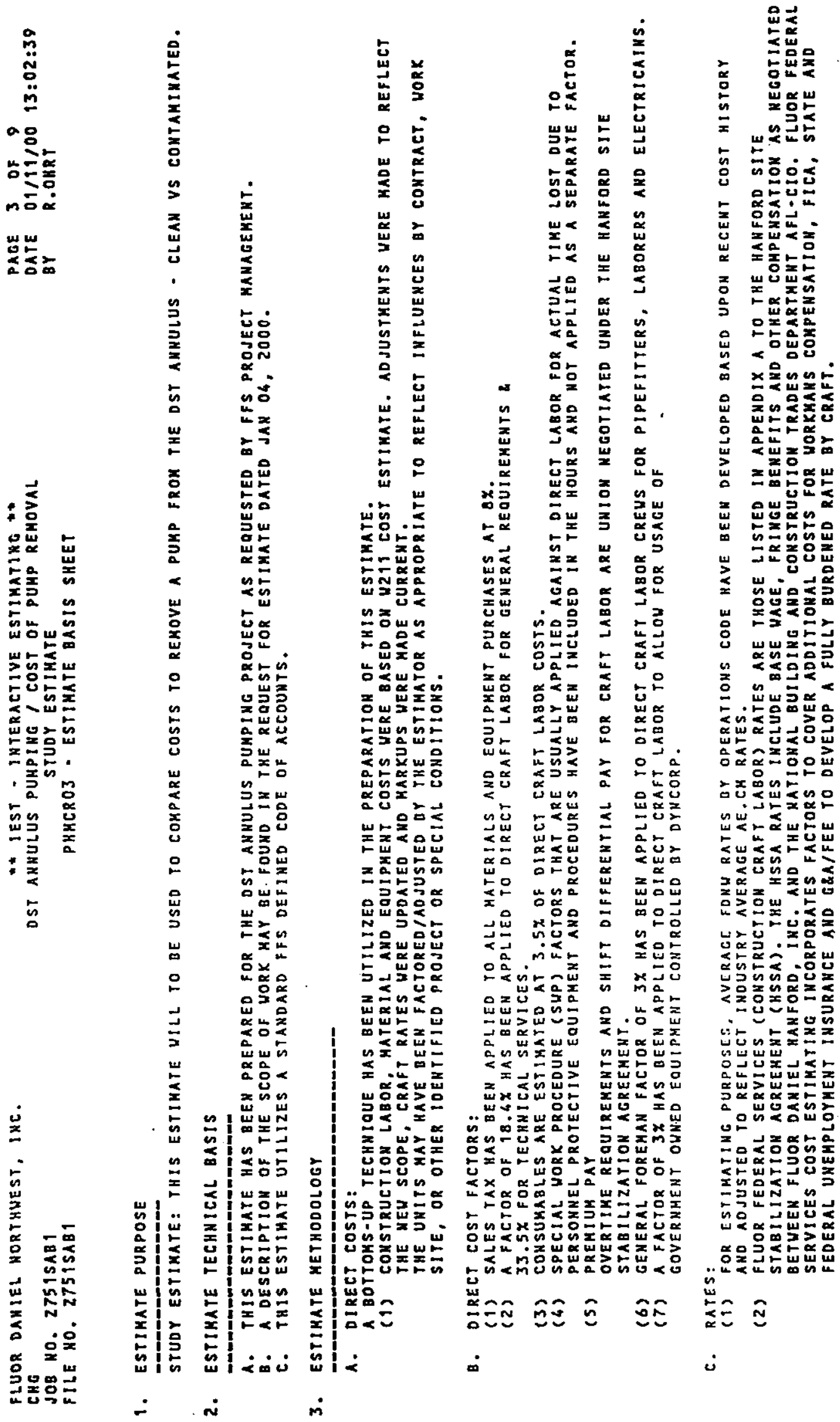


RPP-5842, Rev. O

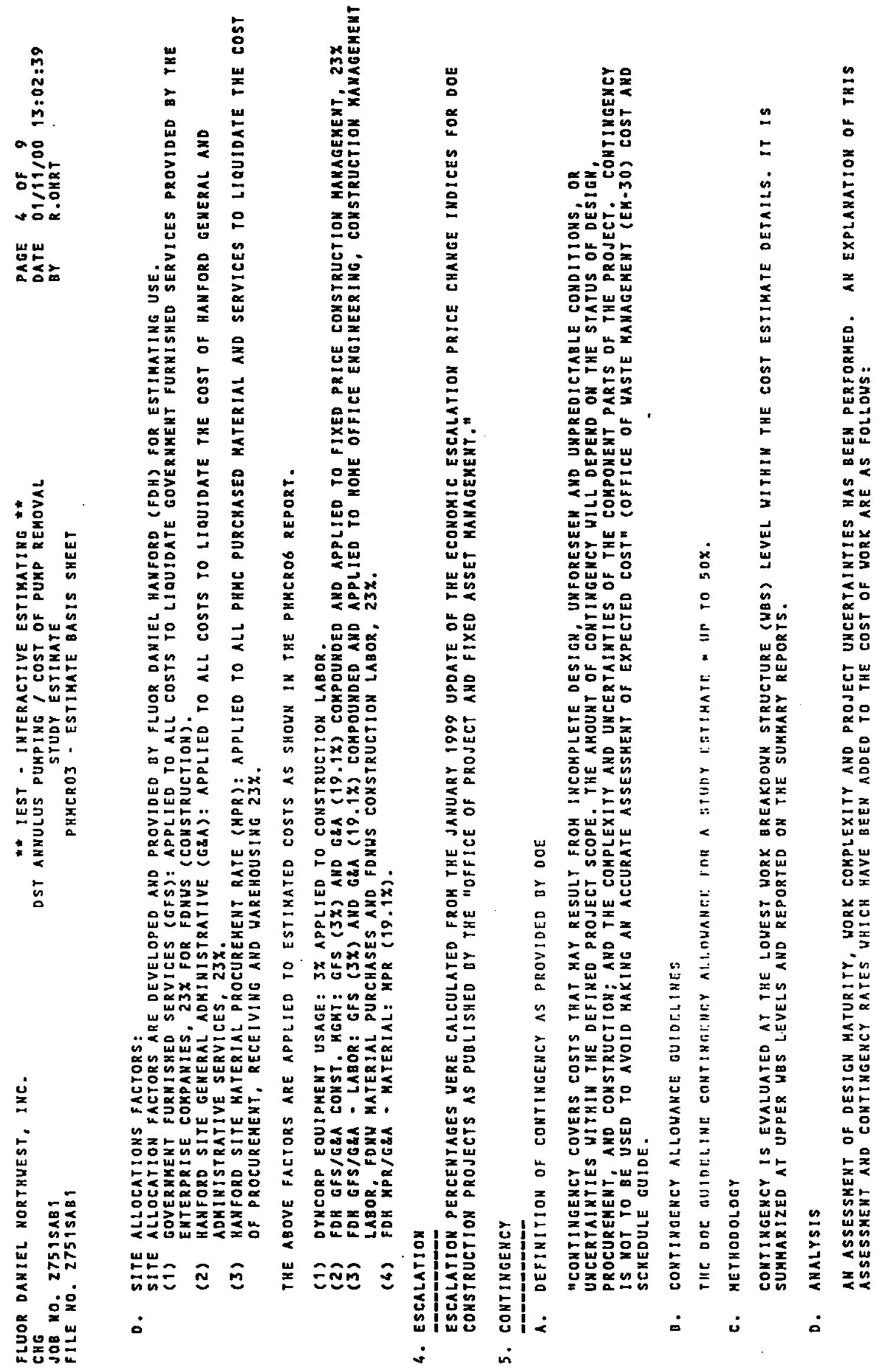




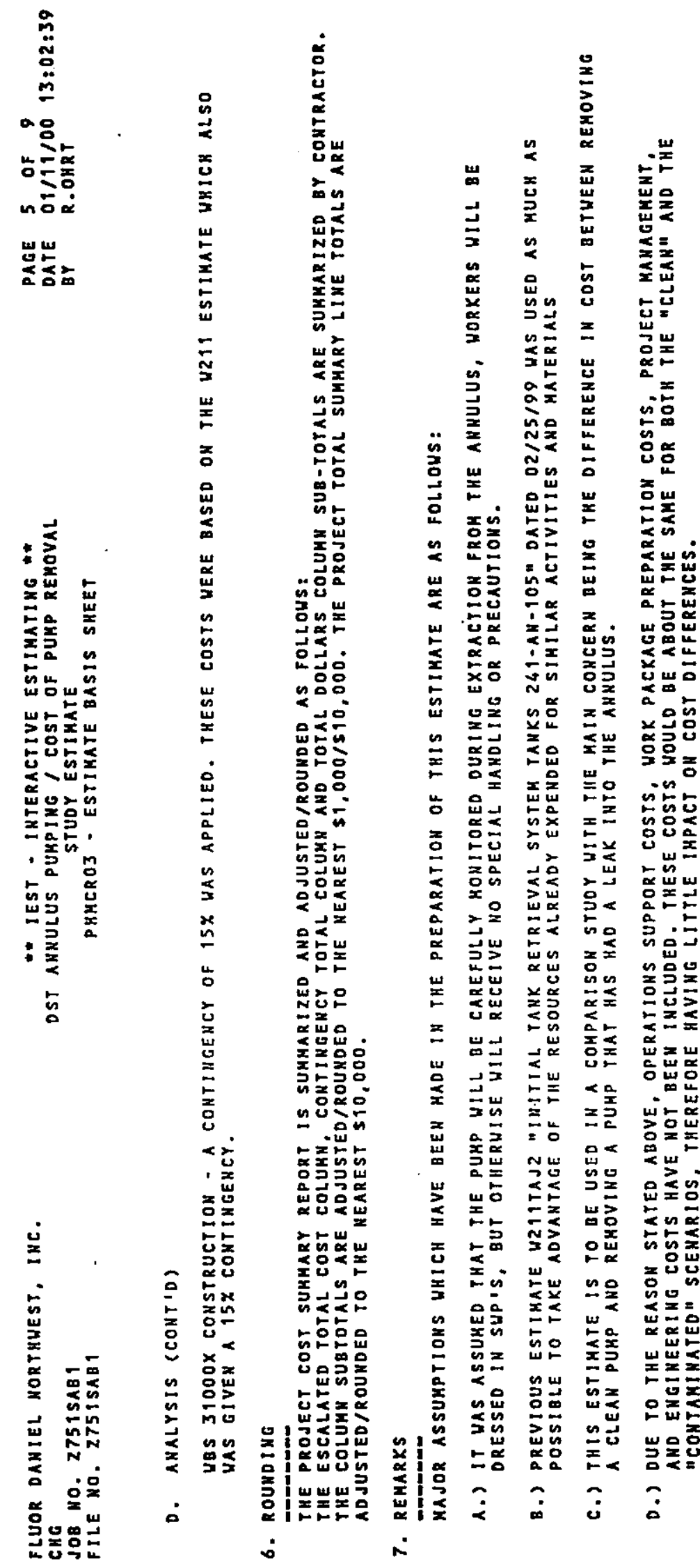


RPP-5842, Rev. 0

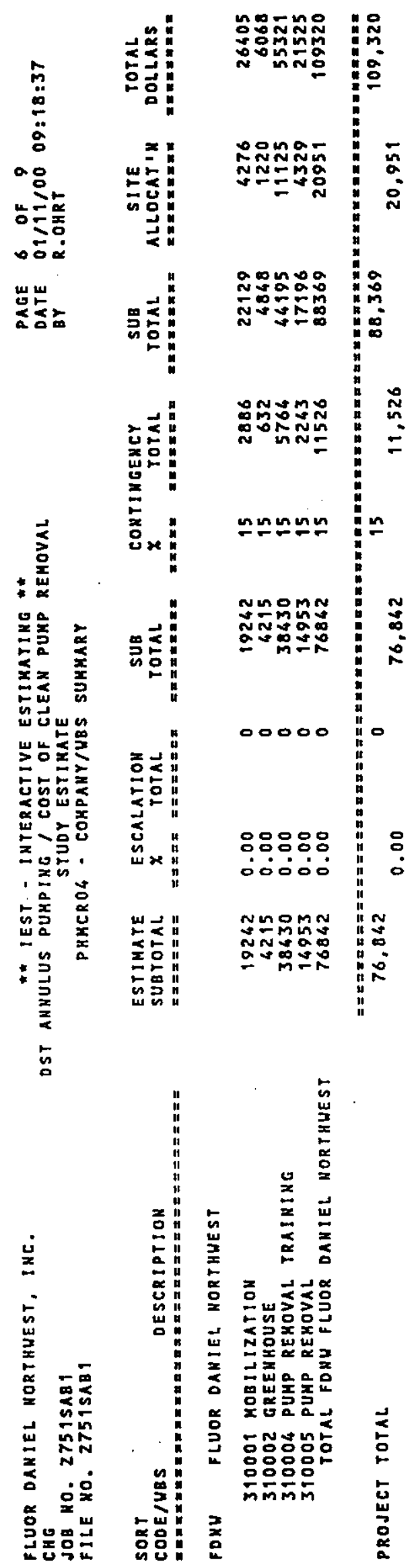




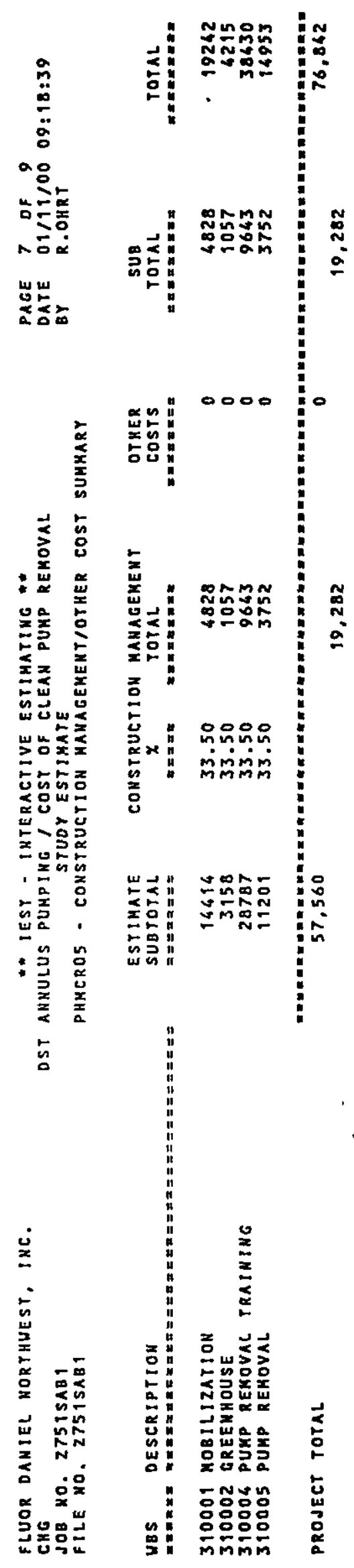




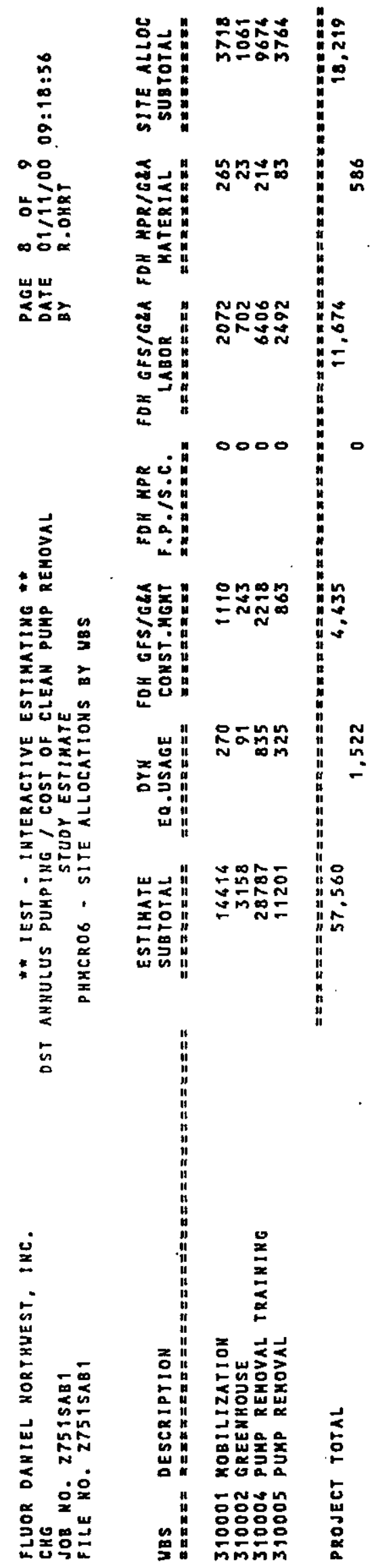




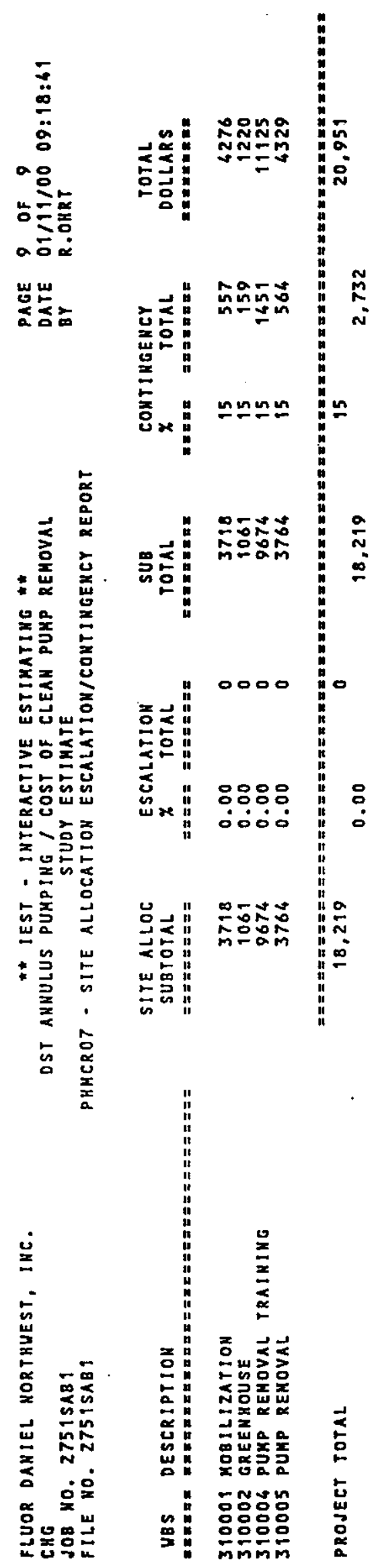


RPP-5842, Rev. 0

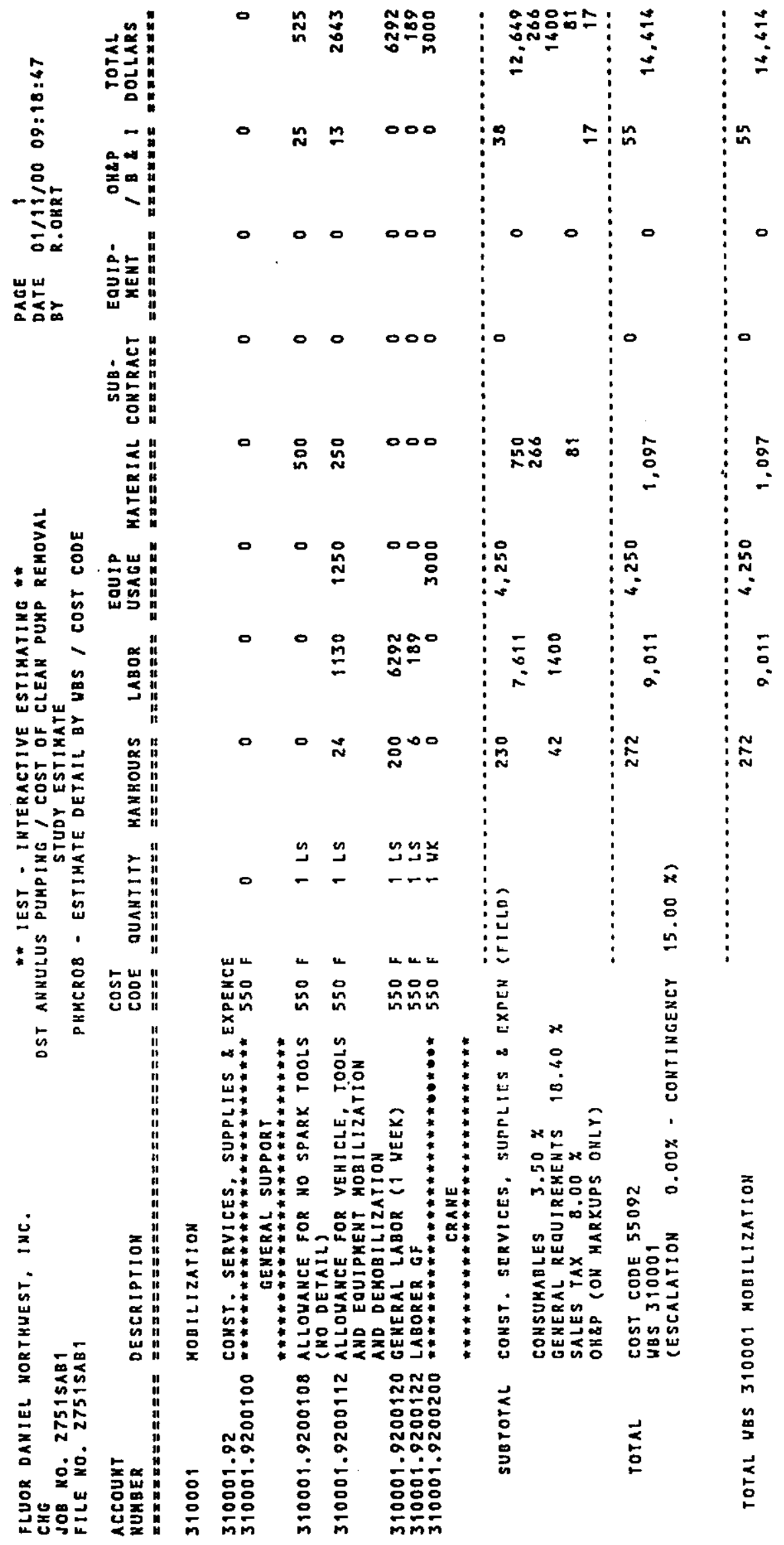


RPP-5842, Rev. 0

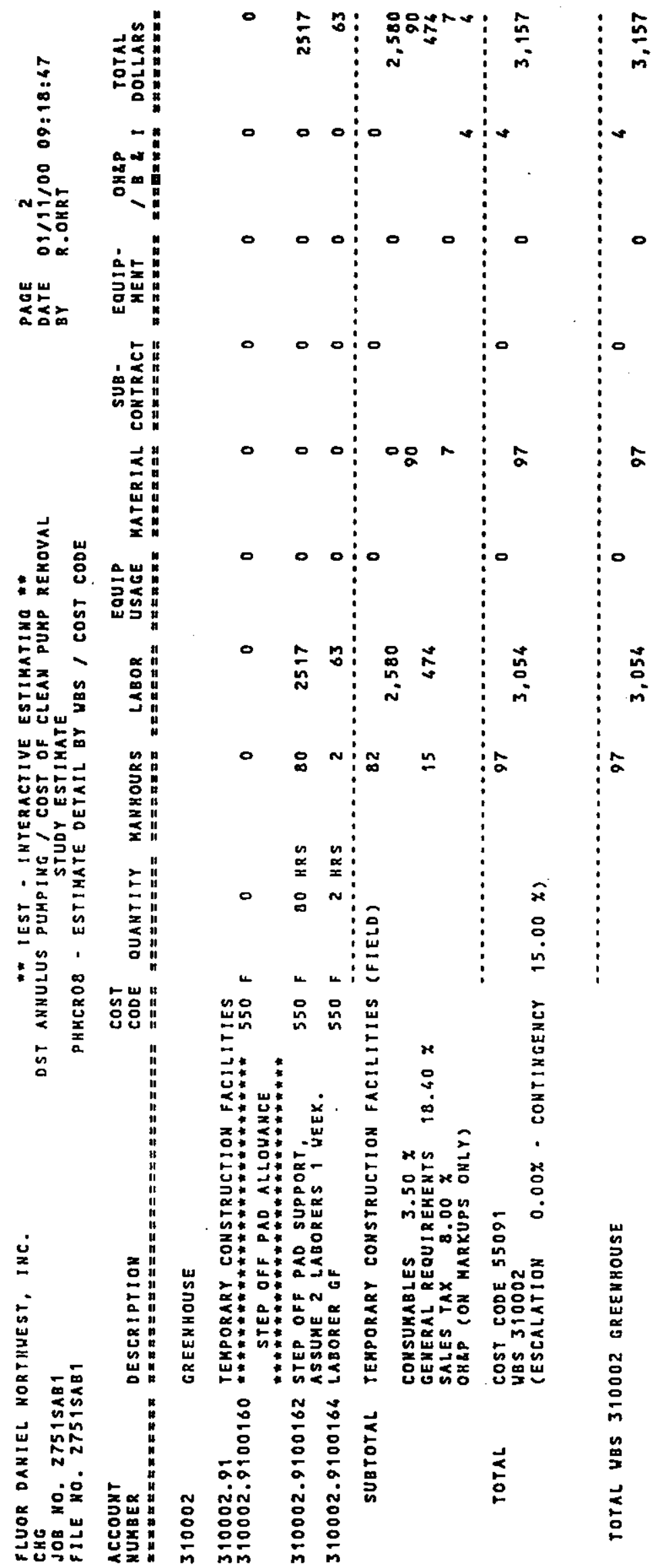




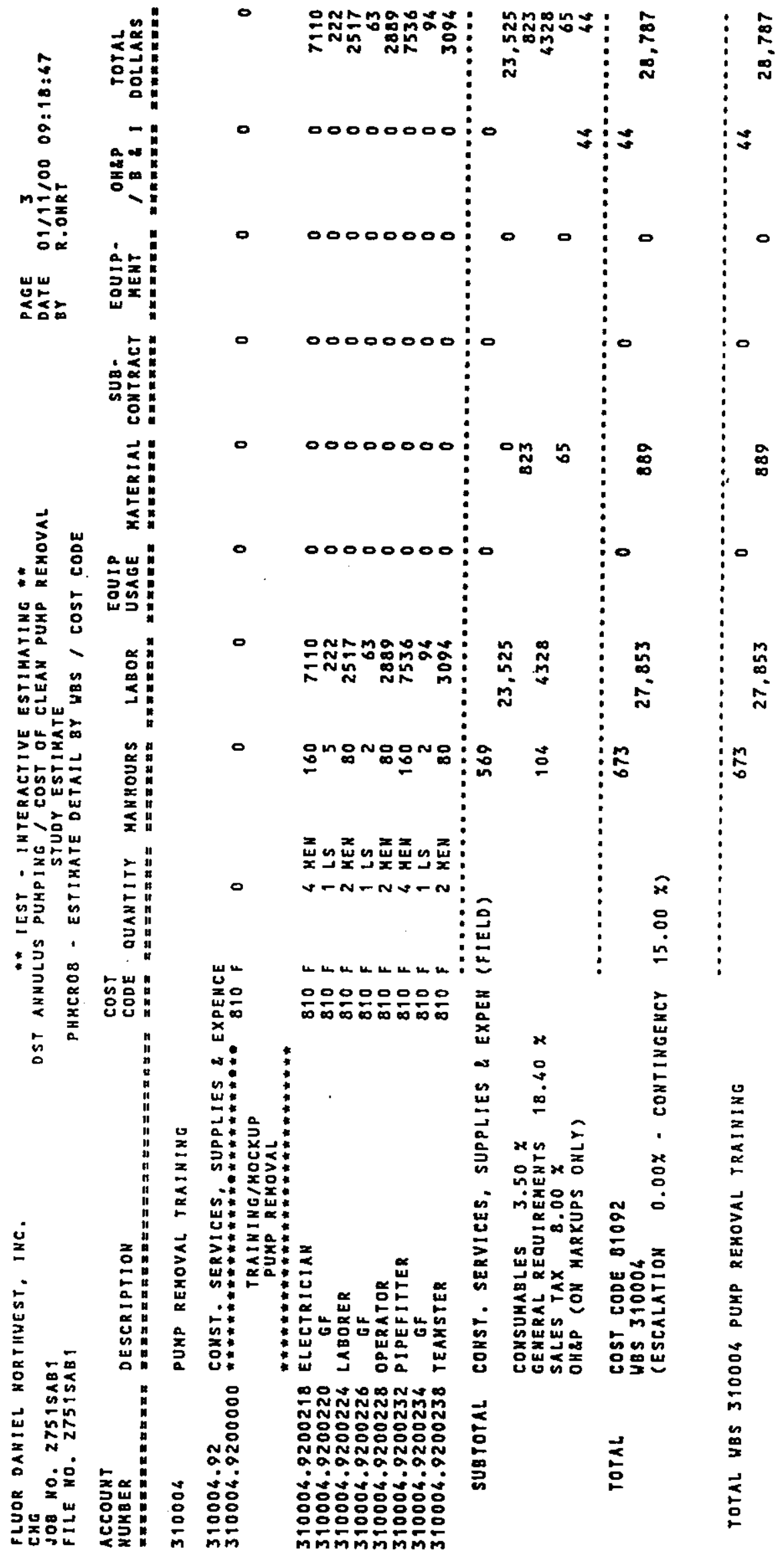




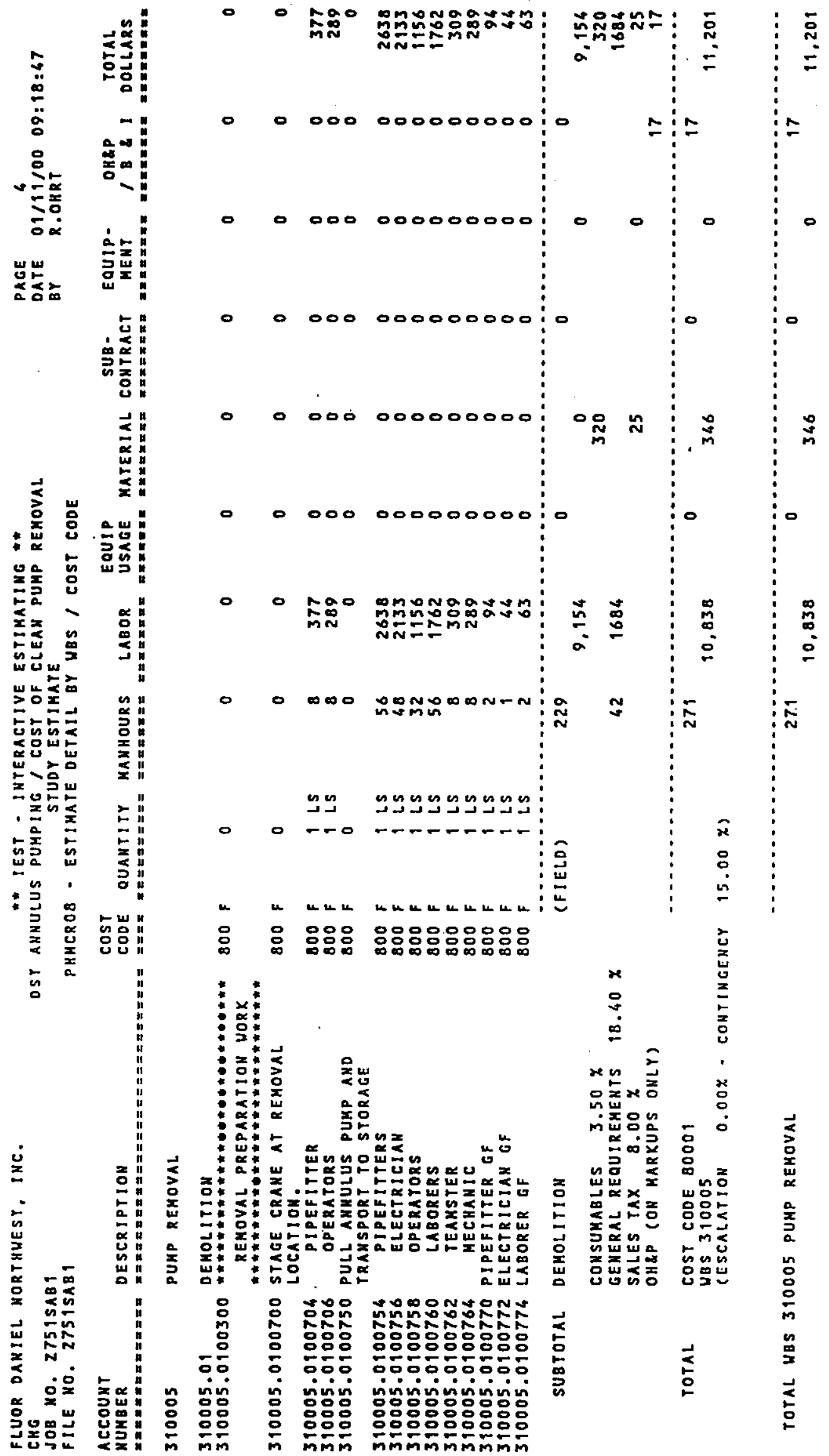




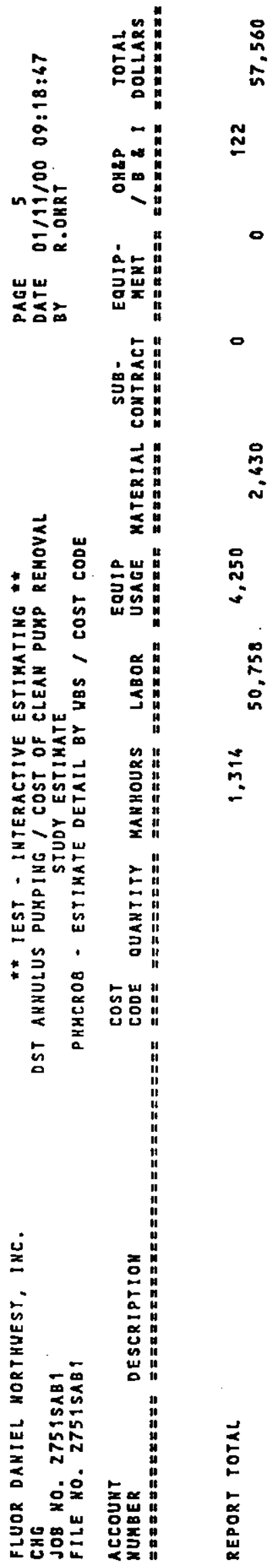


RPP-5842, Rev. 0
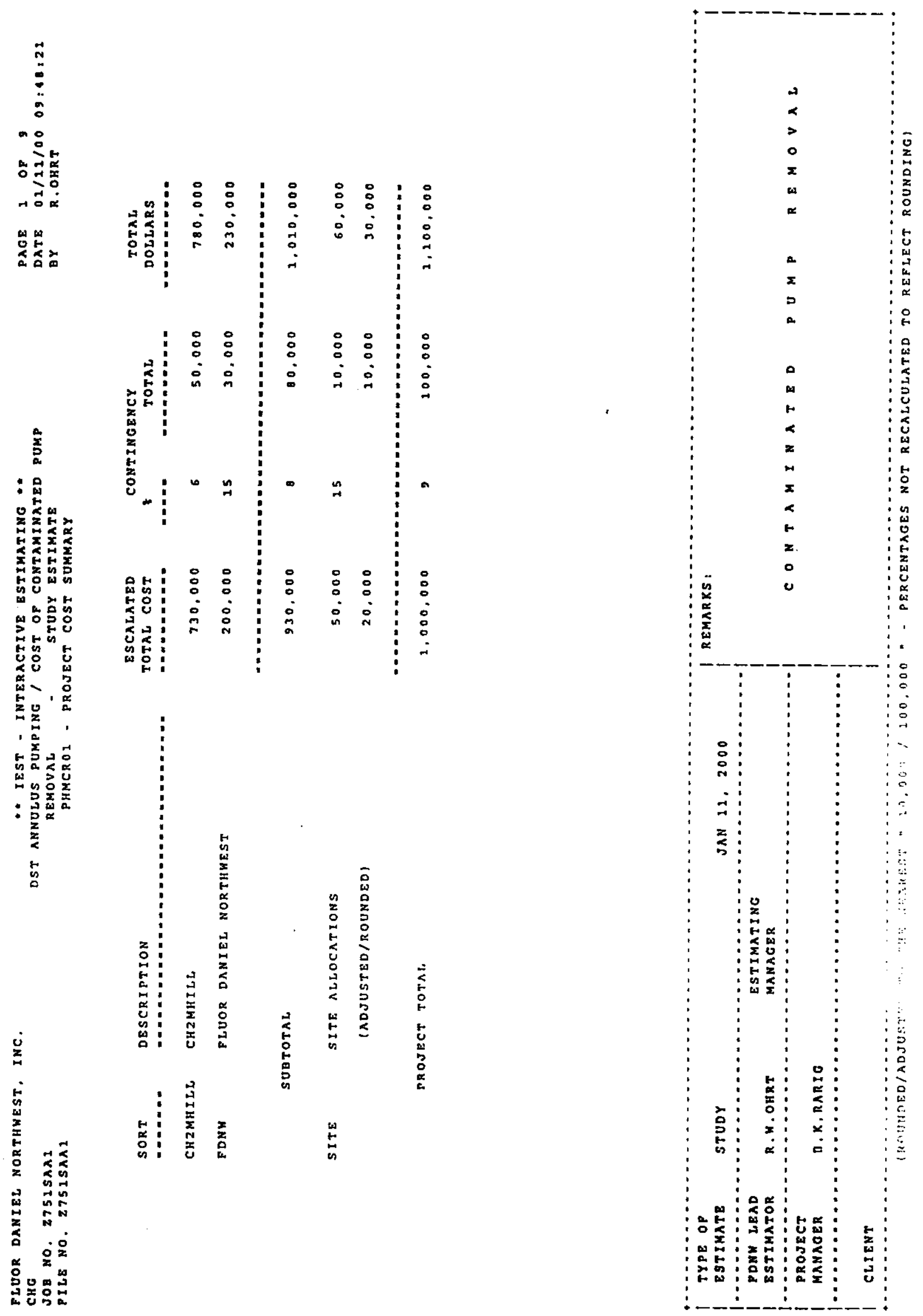
RPP-5842, Rev. 0
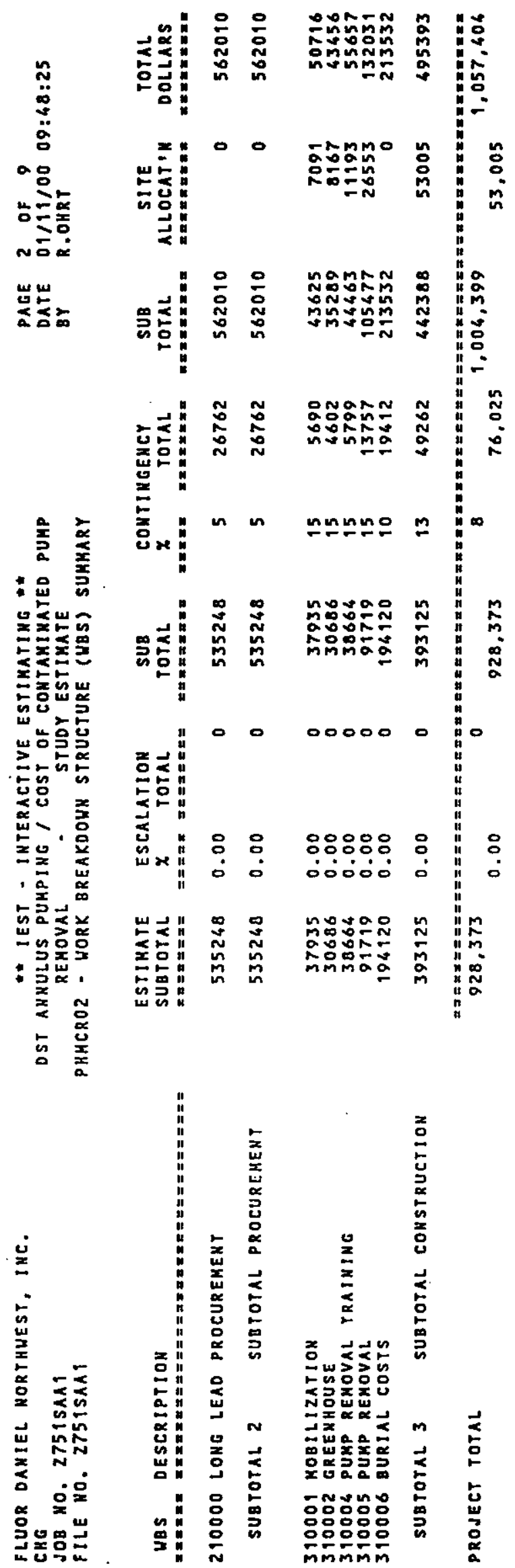


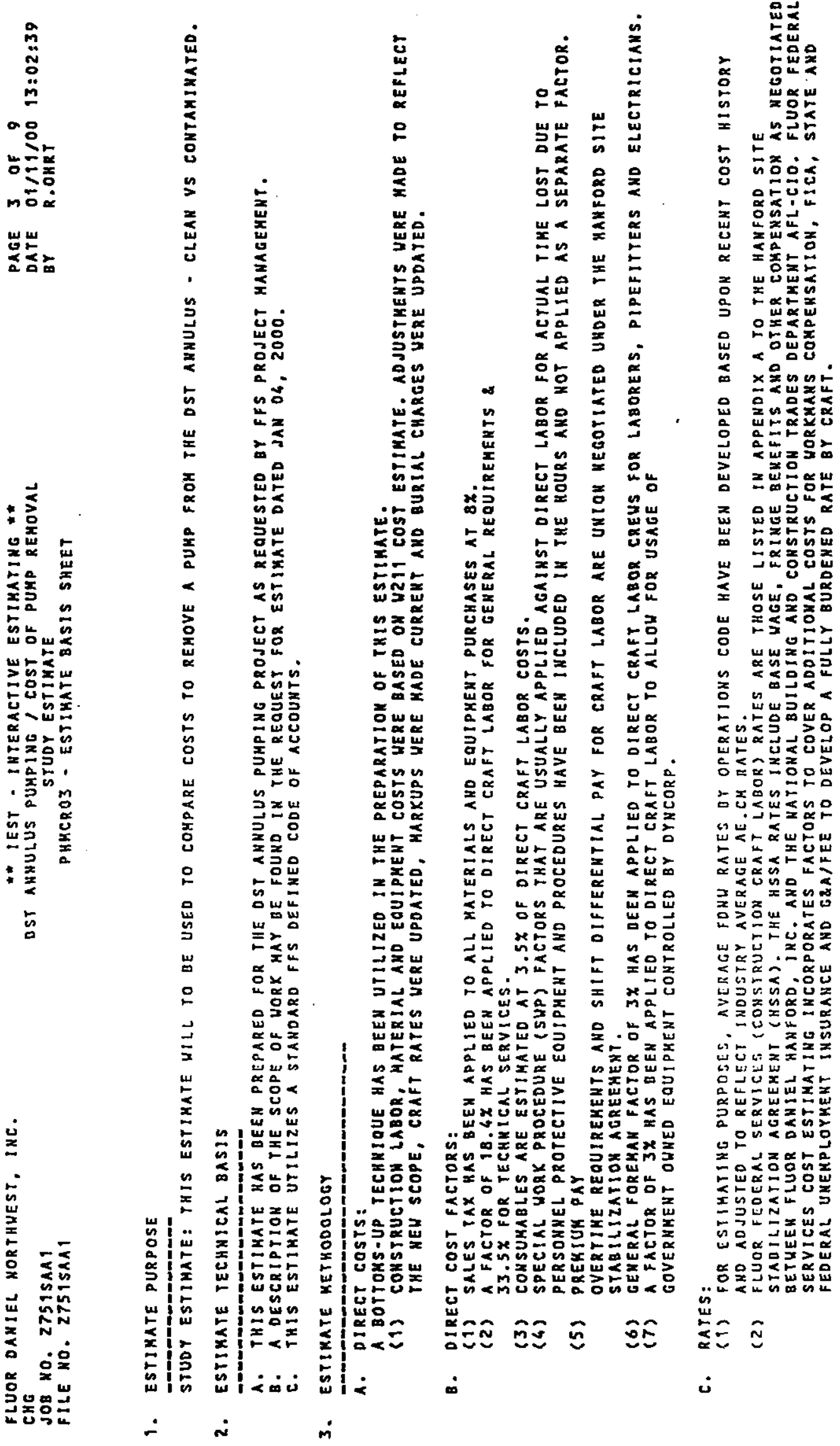


RPP-5842, Rev. 0

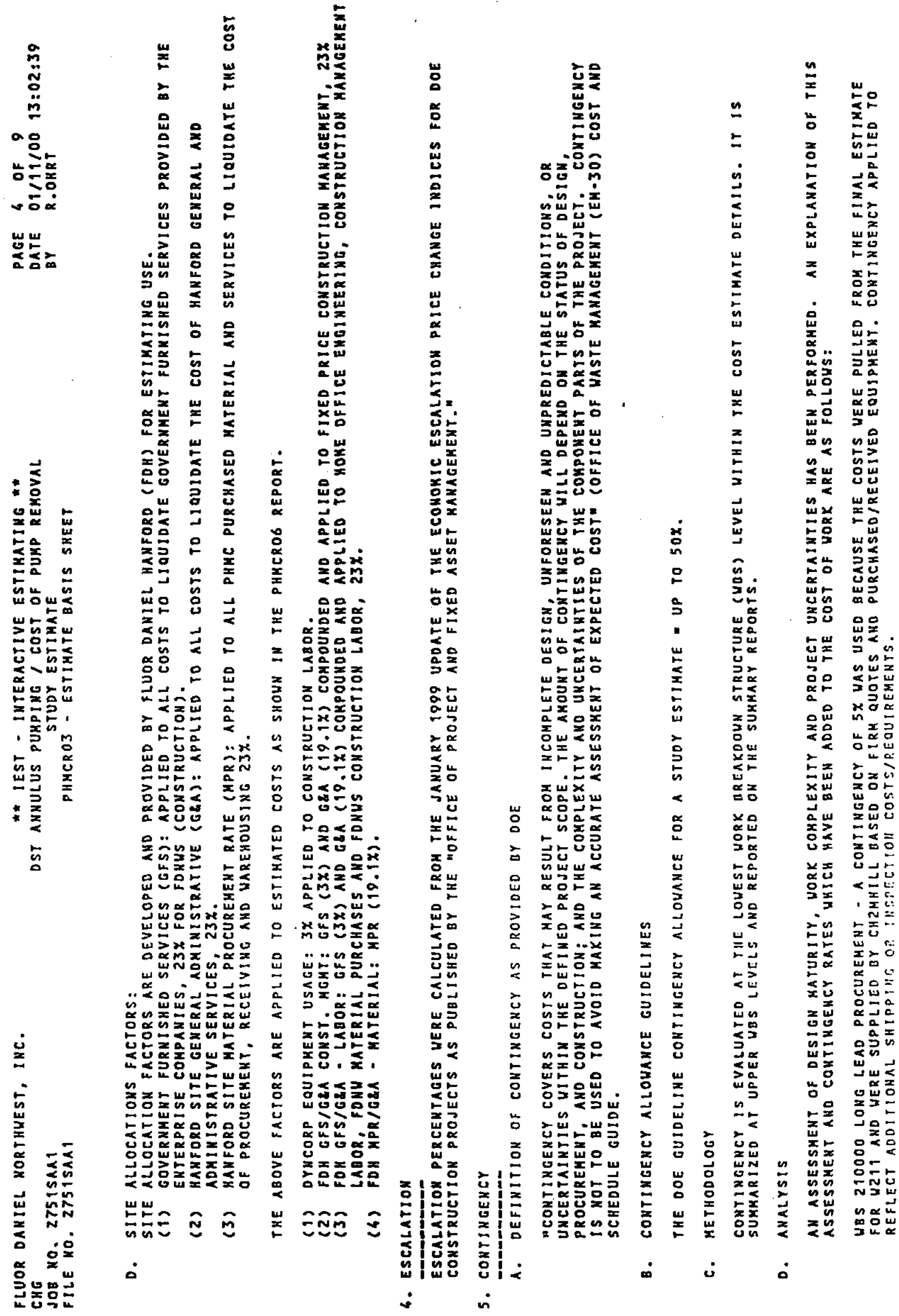




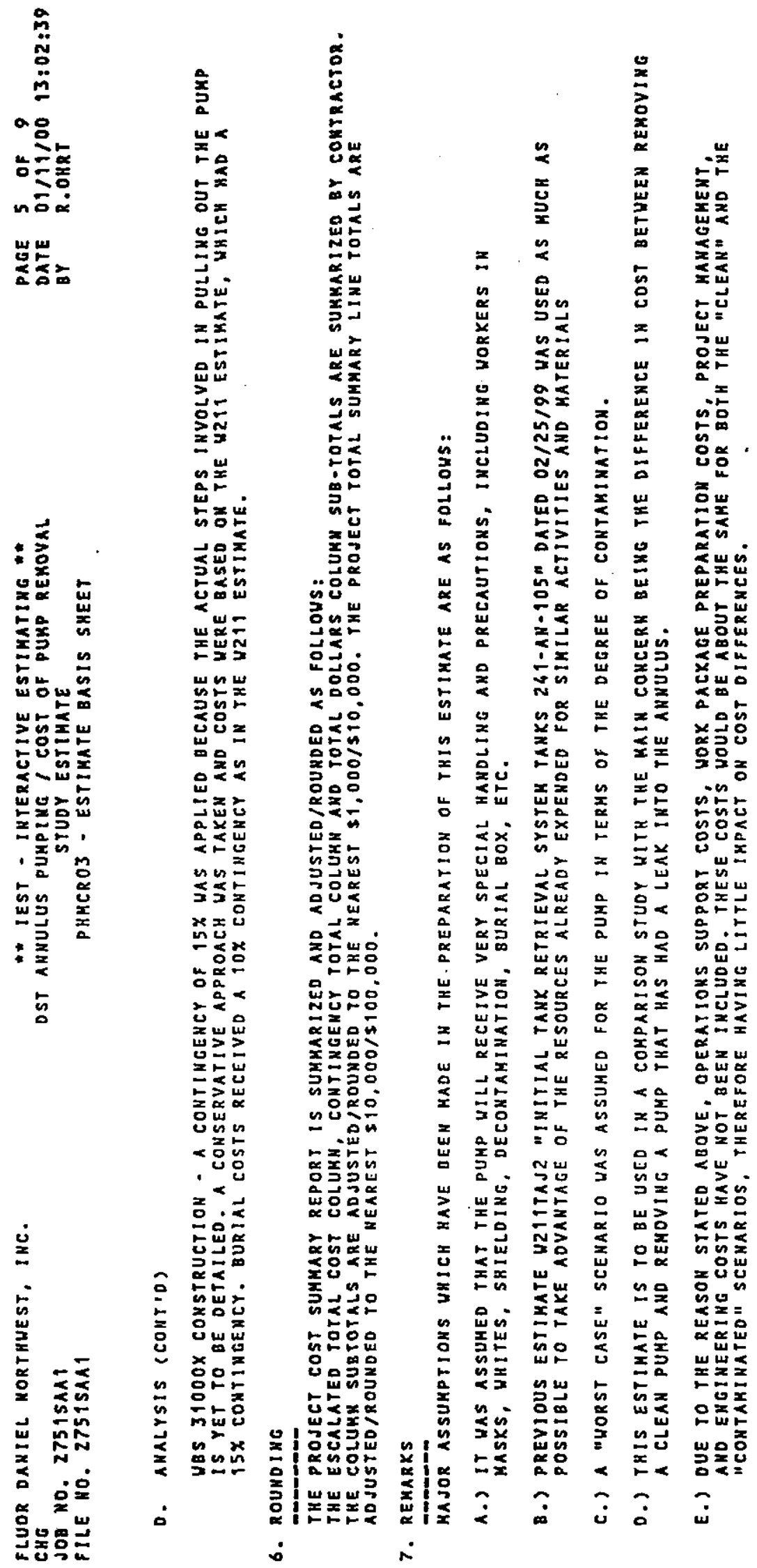




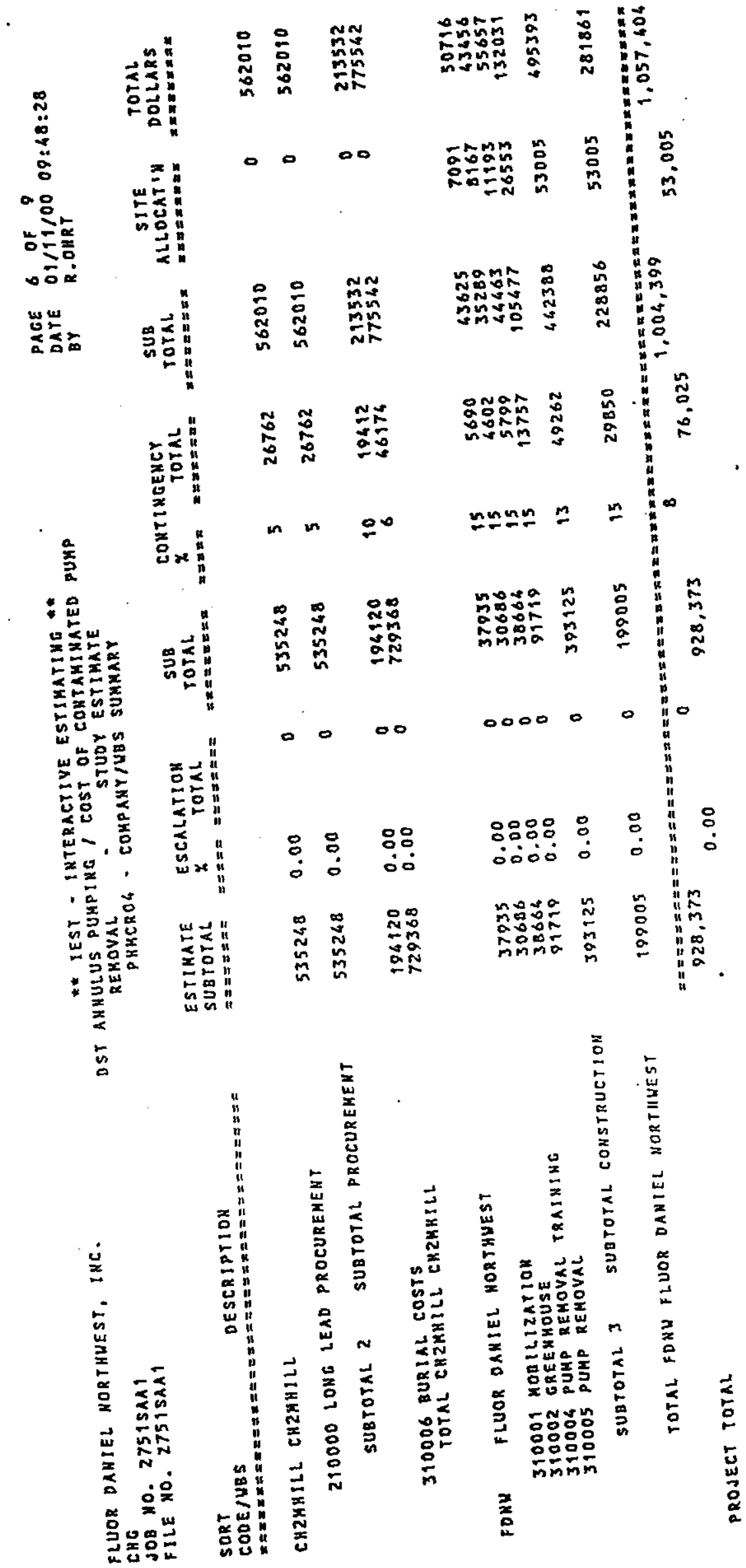


RPP-5842, Rev. 0

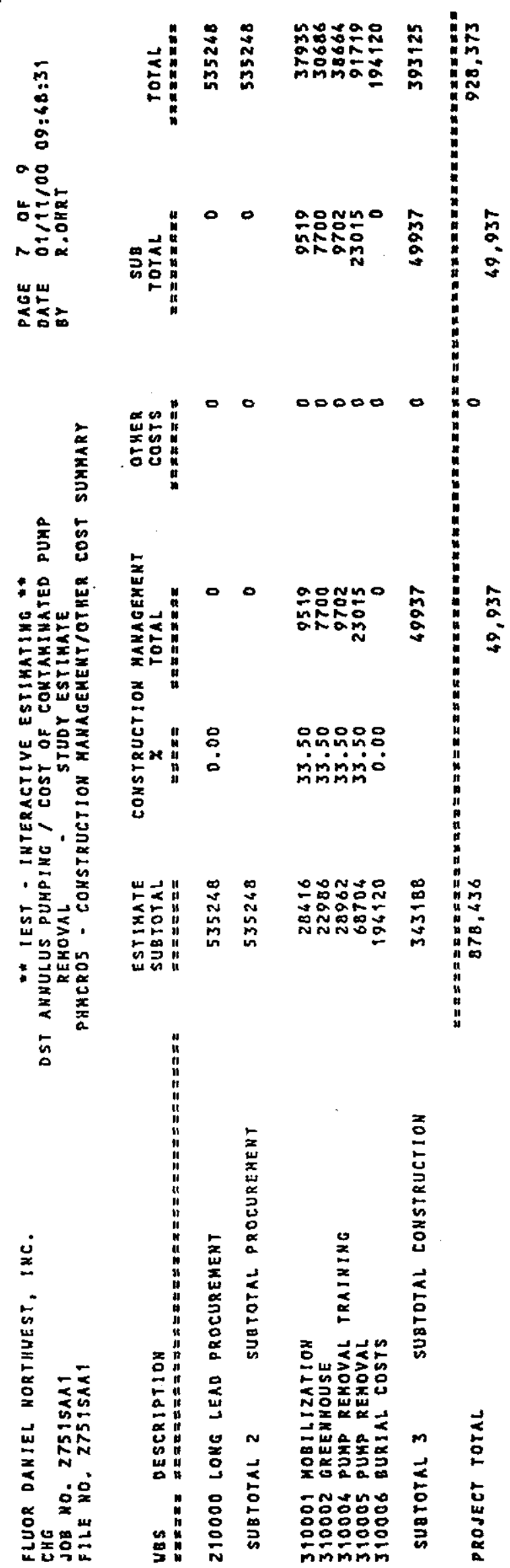




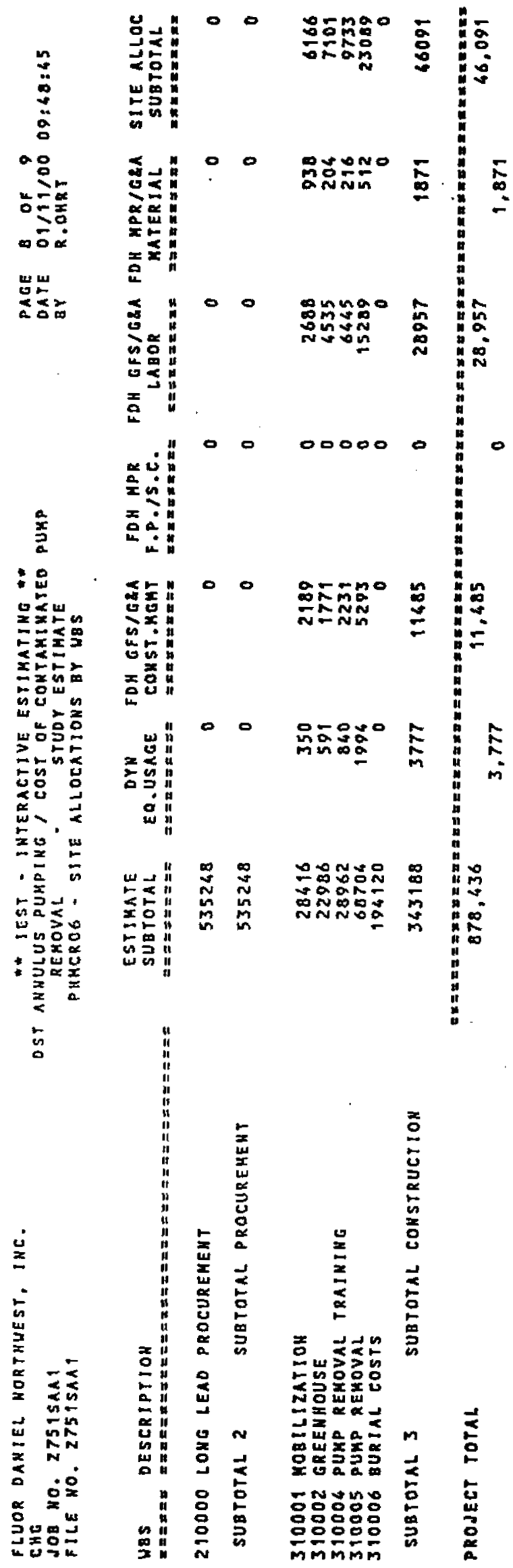


RPP-5842, Rev. 0

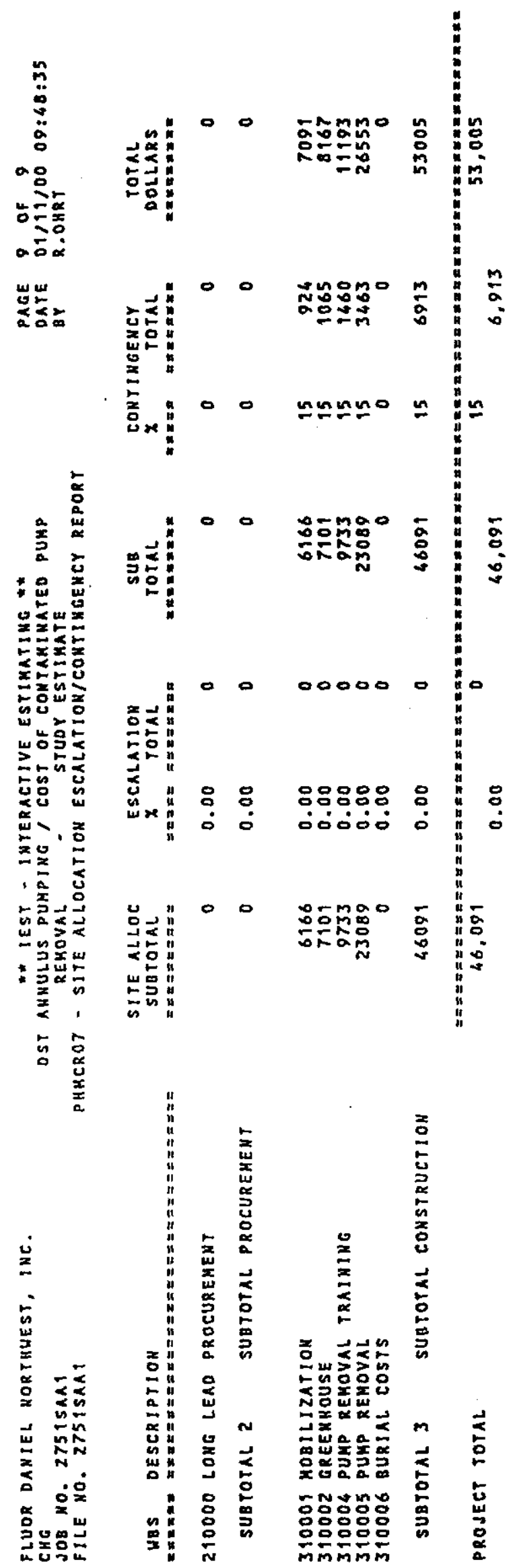




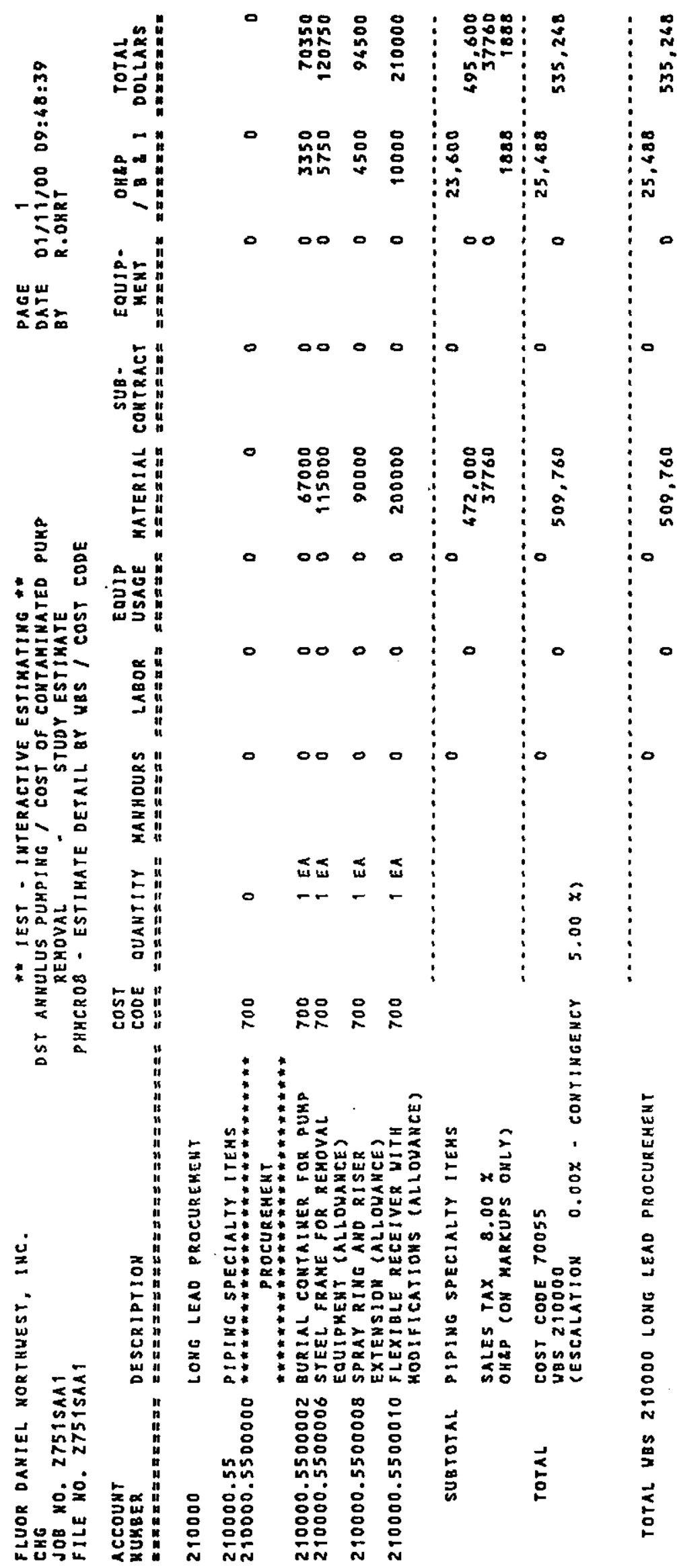




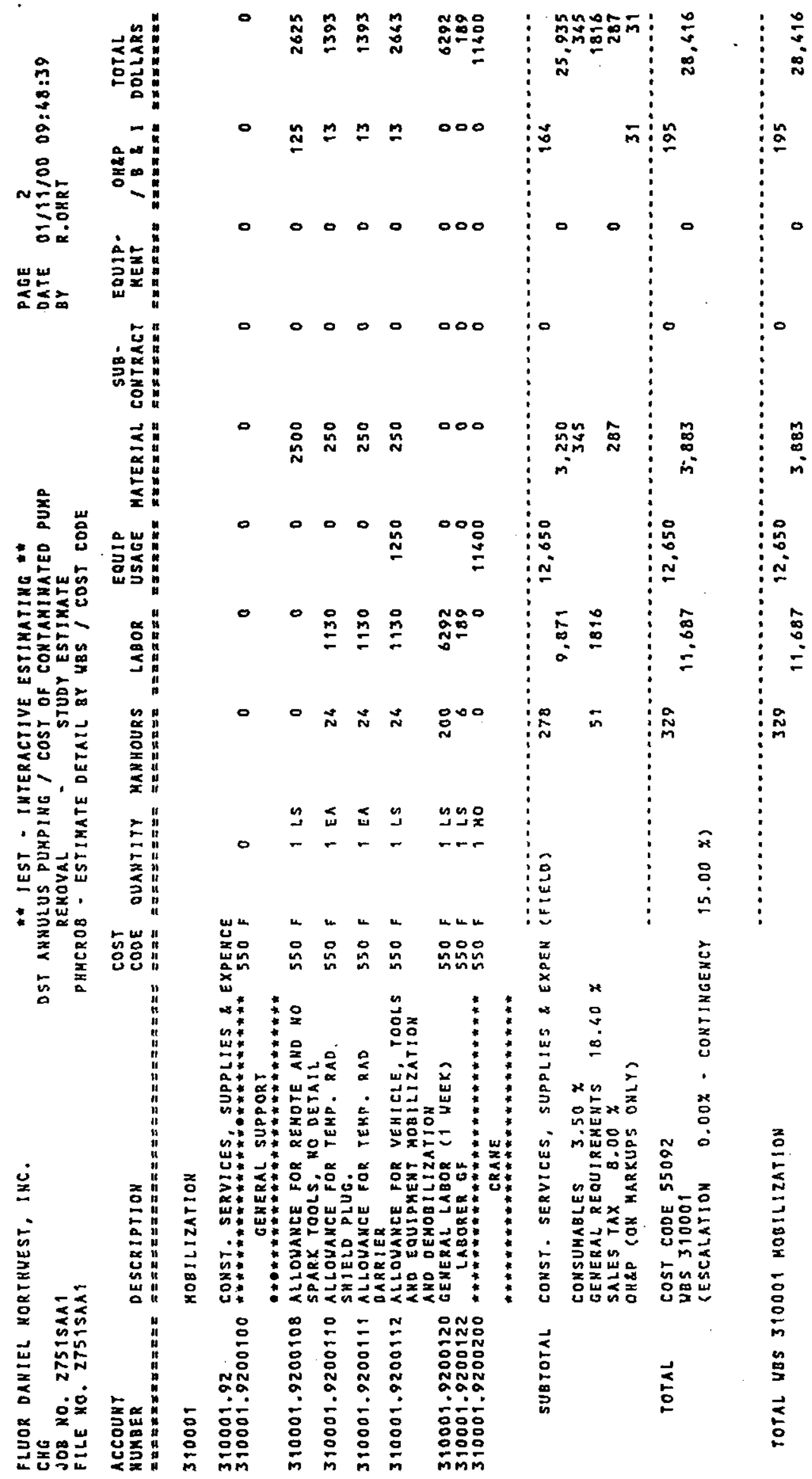




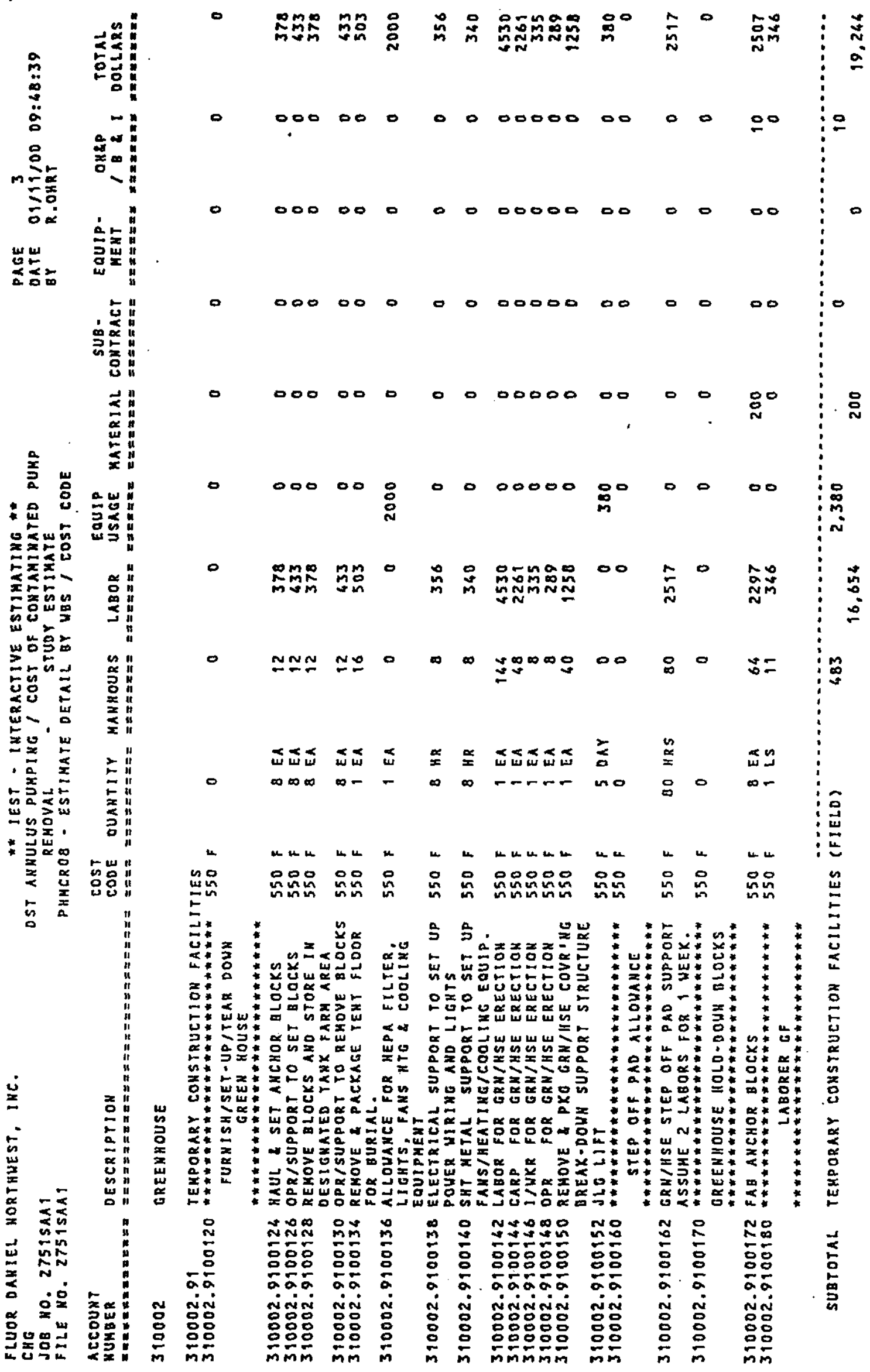


RPP-5842, Rev. 0

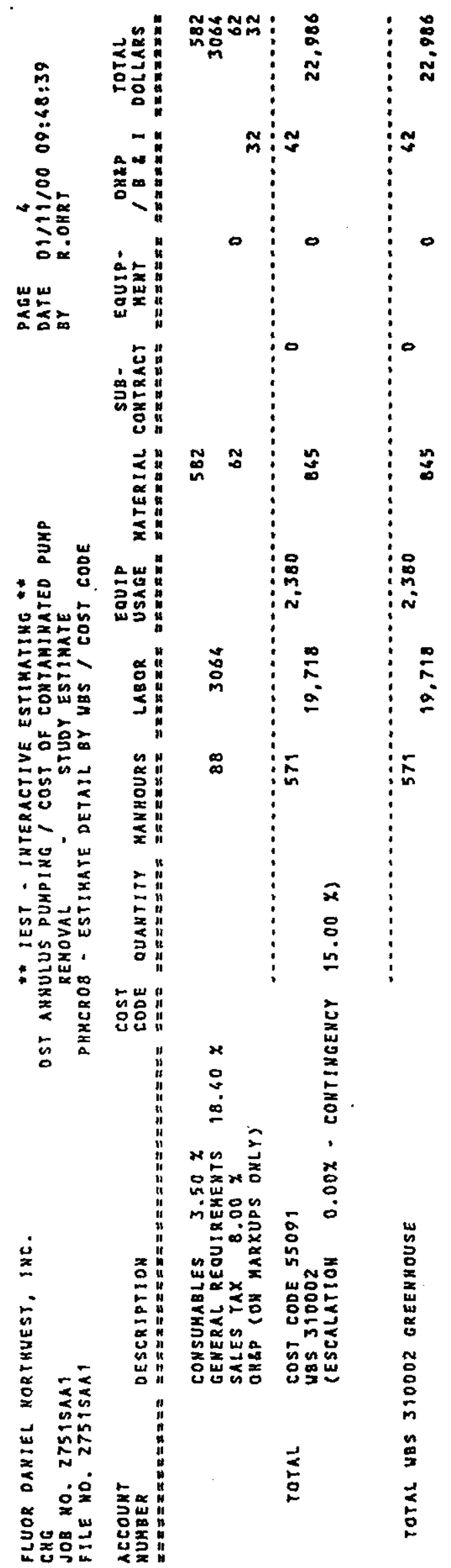




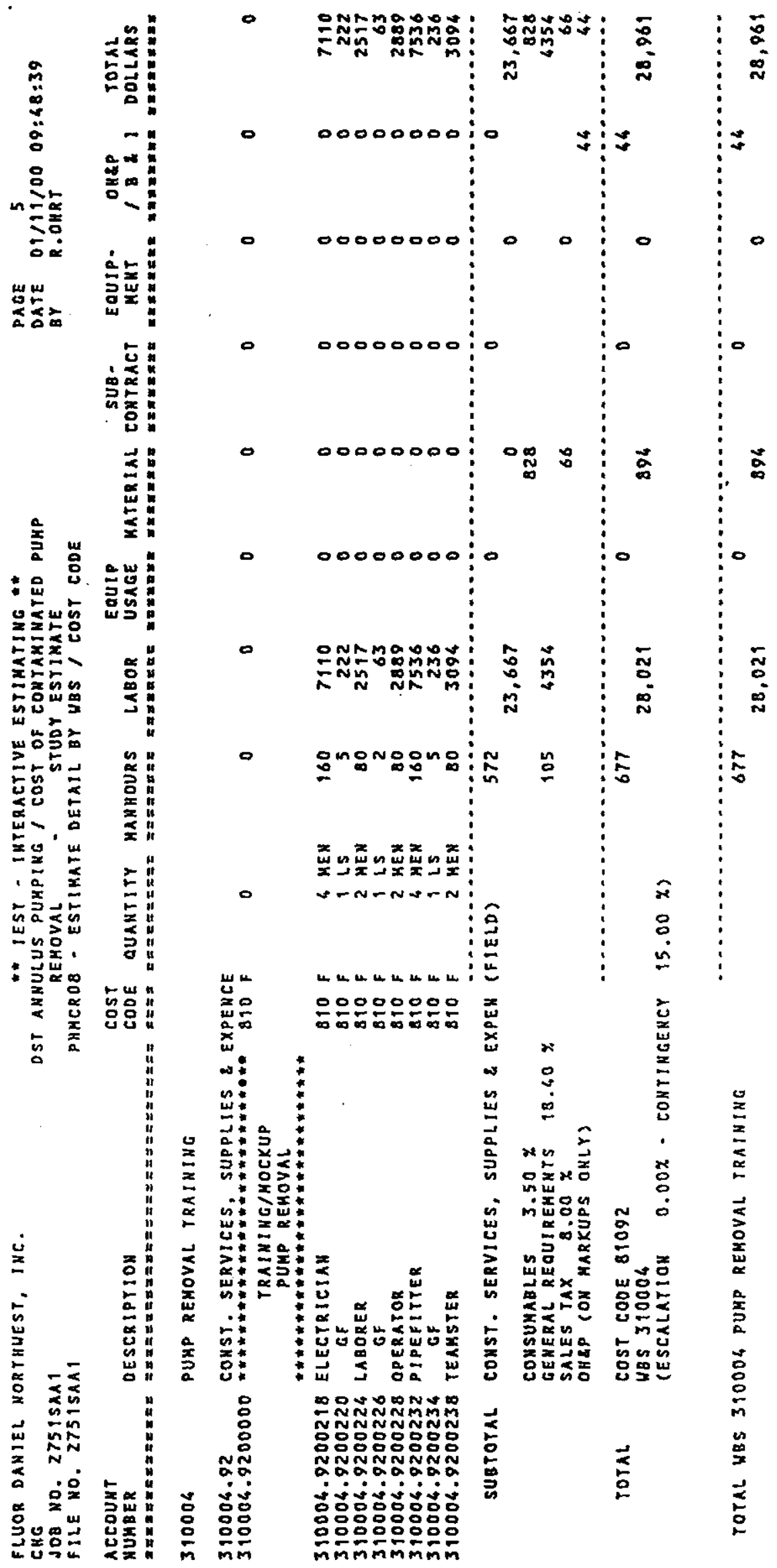




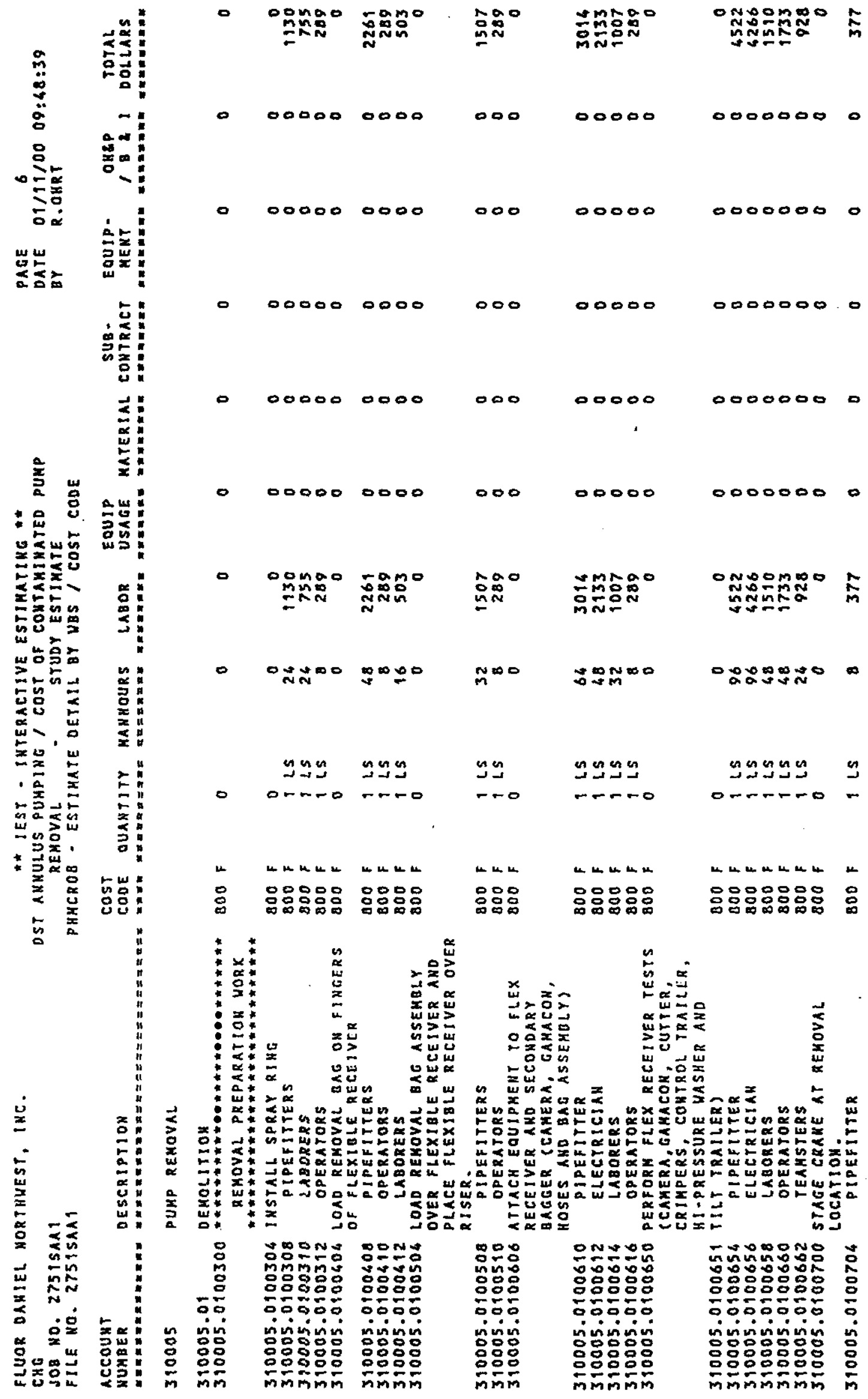




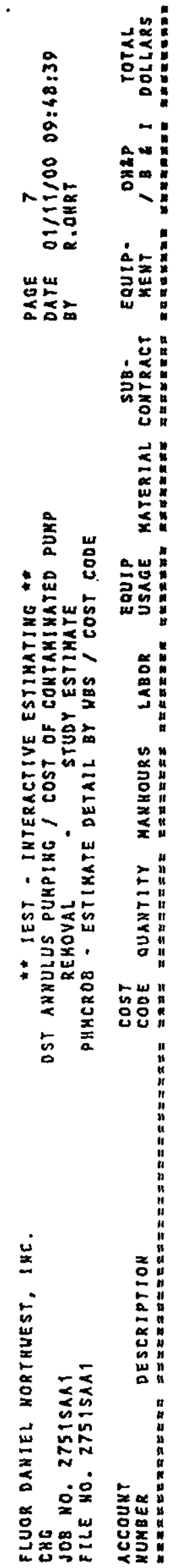

\section{马ำ}

00000000000000000000000

00000000000000000000000

00000000000000000000000

00000000000000000000000

00000000000000000000000

gommbnagorymogontromuno

N

DO

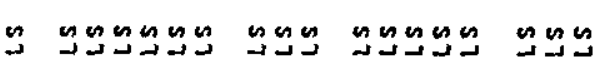

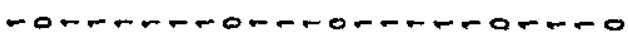

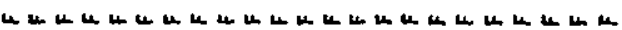

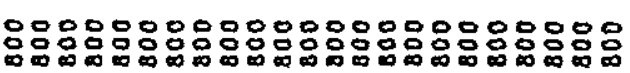

$\boldsymbol{\sigma}$

0

- NONOMNOO

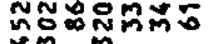

0

000000000

000000000

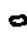

000000000

○

000000000

$\infty$

000000000

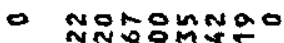

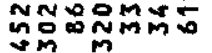

- aN№n:00

ugnengen

$0 \quad 0 \quad-\infty+\infty$

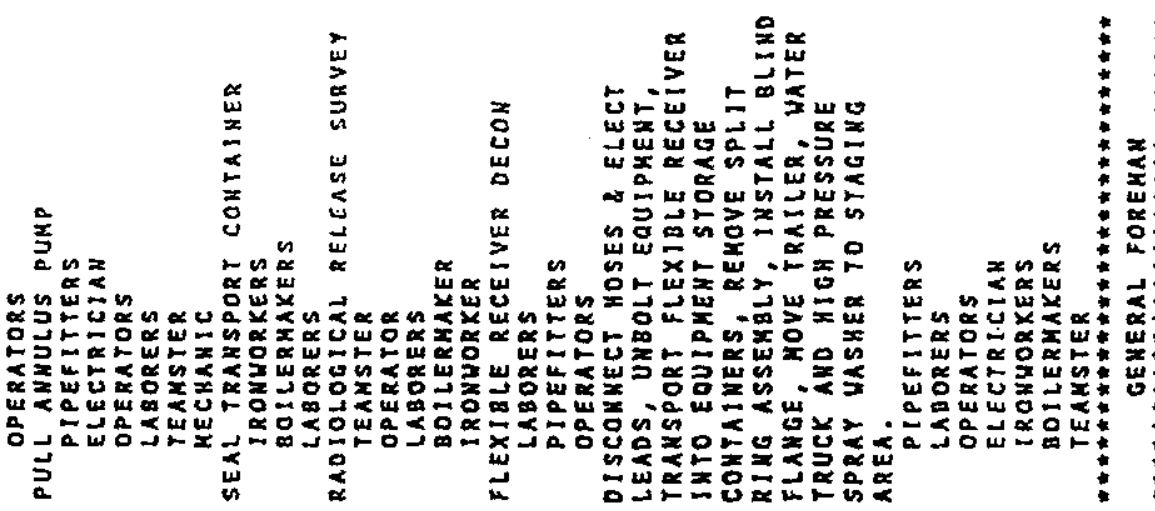

DO+

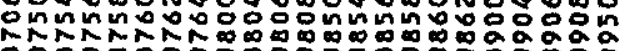

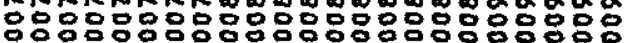

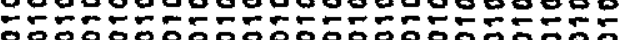
- . . . . . . .

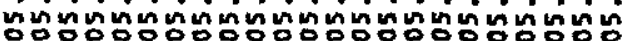

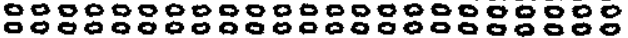

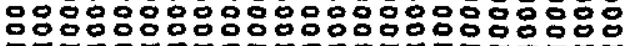
мm

L

O ○ ळ. 


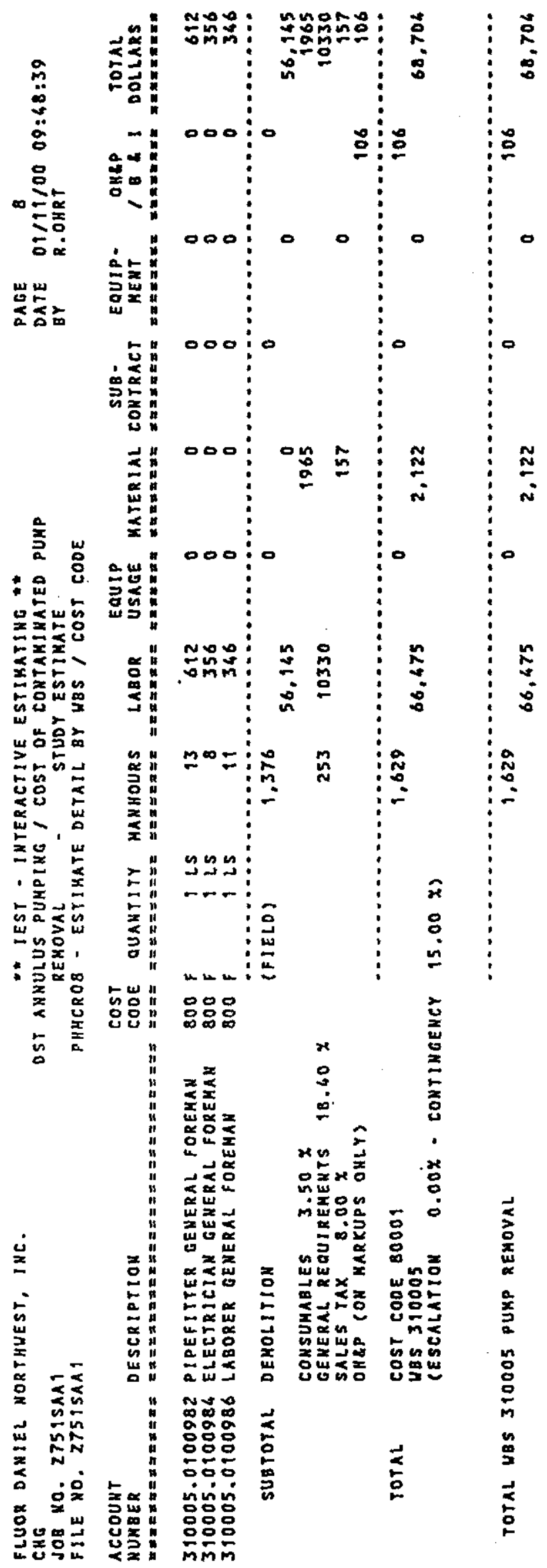




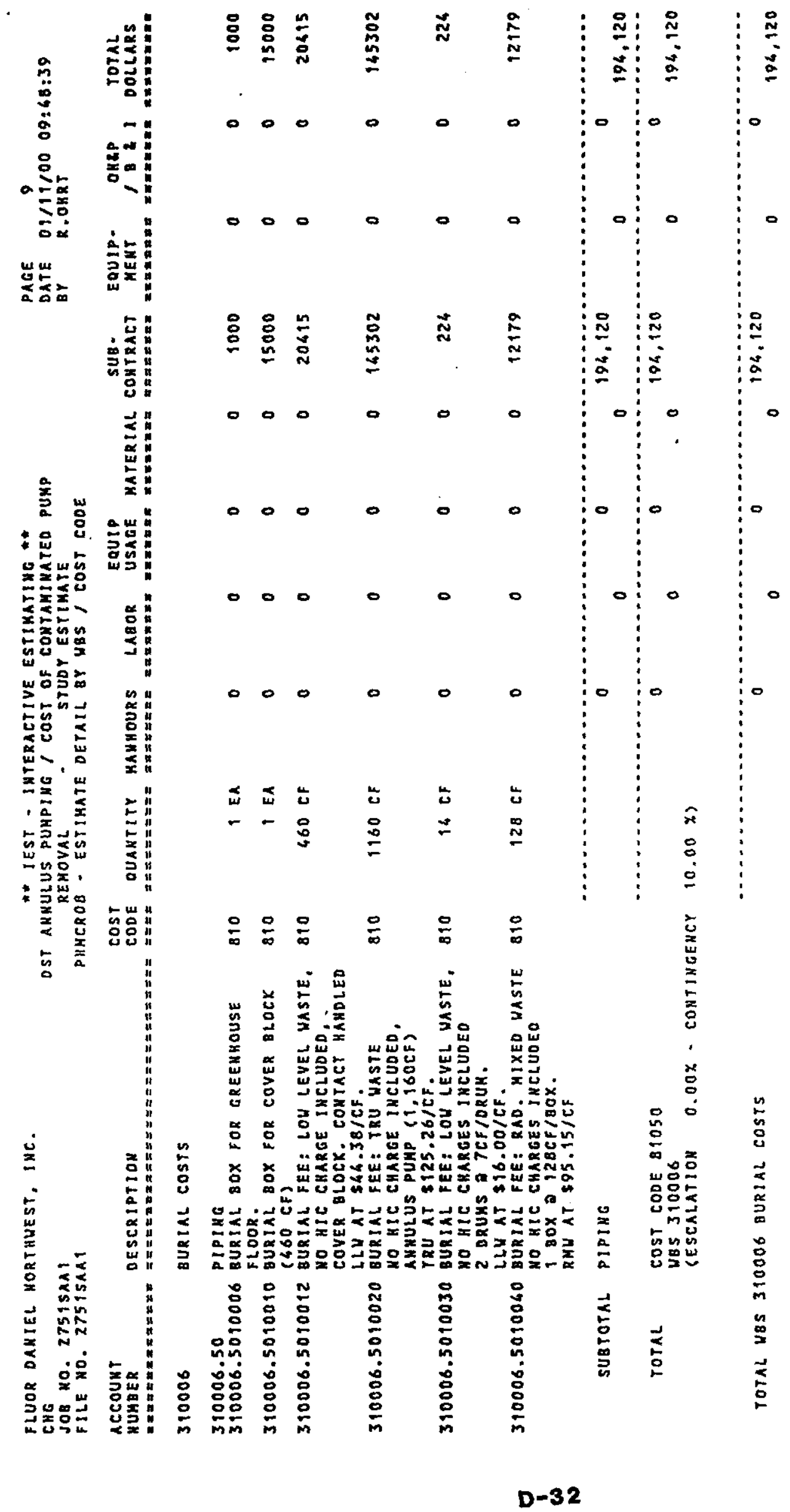


RPP-5842, Rev. 0

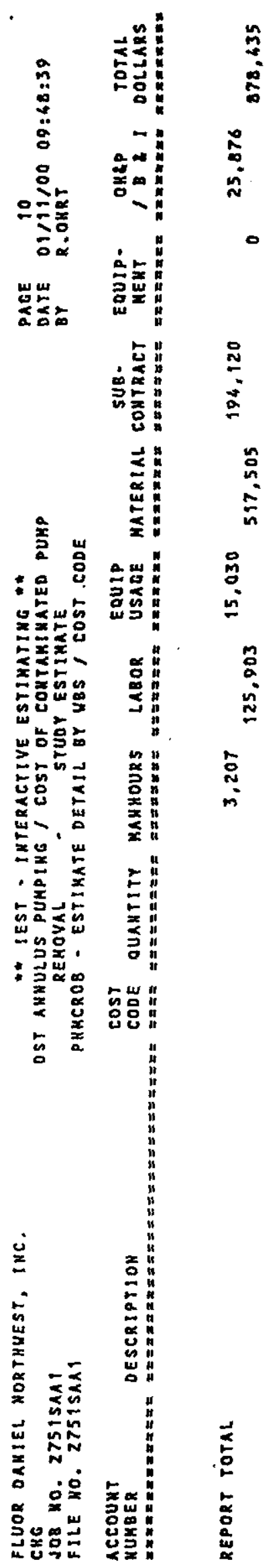




\section{CORRESPONDENCE DISTRIBUTION COVERSHEET}

Author

T. Ambalam, FFS G3-12

Addressee

D. W. Reberger, CHG S5-13

Correspondence No.

subject: TIME DEPLOYMENT STUDY FOR ANNULUS PUMPING

\section{DISTRIBUTION}

\begin{tabular}{|c|c|c|c|c|}
\hline Approval & Date & Name & Location & w/att \\
\hline & & Correspondence Control & A3-01 & \\
\hline & & R.W. Reed & T4-07 & \\
\hline & & D.G. Baide & S5-05 & \\
\hline & & M.J. Sutey & S5-07 & \\
\hline & & P.C. Miller - 4 copies & R1-51 & . \\
\hline & & R.E. Larson & T4-07 & \\
\hline & & H.R. Hopkins & R2--58 & \\
\hline & & J.J. Badden & S5-07 & \\
\hline & & M.H. Brown & T4-07 & \\
\hline & & D.W. Reberger - 4 copies & S5-13 & \\
\hline & & B.K. Rarig & G3-15 & \\
\hline & & F.M. Hauck & A3-04 & \\
\hline & & C.E. Shipler & $S 2-25$ & \\
\hline & & S.J. Lepka & S2-25 & \\
\hline & & L.K. Martin & S2-25 & \\
\hline
\end{tabular}

